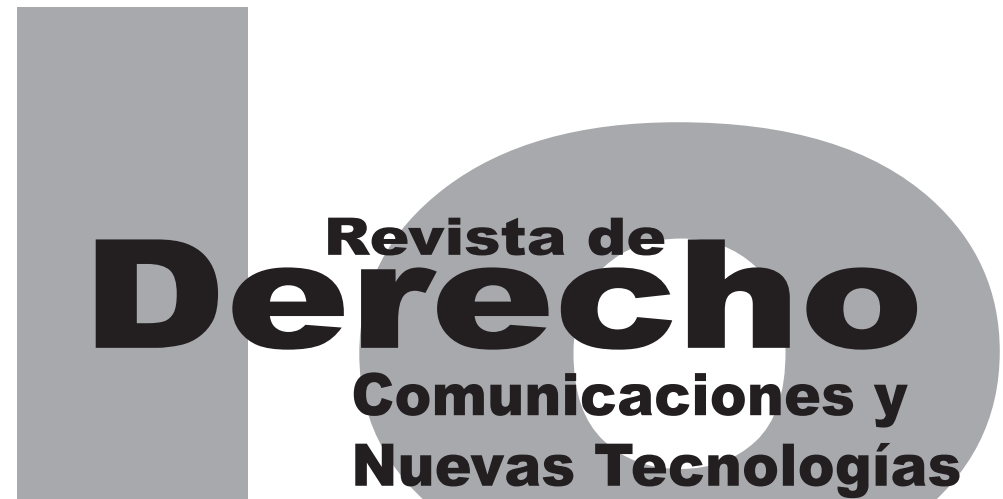

\title{
LA FUNCIÓN SOCIAL DEL DERECHO DE AUTOR
}

\author{
Julio César Padilla HerRera
}

\author{
Artículo de reflexión
}

DOI: http://dx.doi.org/10.15425/redecom.14.2015.08

Universidad de los Andes

Facultad de Derecho

Rev. derecho comun. nuevas tecnol.

No. 14, julio - diciembre de 2015. ISSN 1909-7786 


\section{La función social del derecho de autor}

\section{Resumen}

La función social ha tenido múltiples usos en el derecho de propiedad privada. La expropiación, servidumbres o extinción de dominio son solo algunas de las formas concretas en que se hace operativa. Podemos inferir entonces, que más que una definición específica es una idea fuerza que al no tener un contenido único sirve y ha servido como herramienta para la concreción de valores humanos como la igualdad y la solidaridad. En el derecho de autor existen lecturas y usos de la función social que, sin embargo, no han conocido las formas concretas de la propiedad sobre tangibles; a pesar de esto, ha estado implícita -y en algunos casos explícita- en el centro de la crítica moderna a la institución. Mediante un enfoque crítico, este texto presenta esas lecturas de la función social en el derecho de autor y propone, dada la posibilidad interpretativa de esta idea fuerza, una lectura posible.

Palabras clave: propiedad intelectual, función social, derecho de autor, expropiación, limitaciones y excepciones, dominio público, solidaridad, educación.

\section{A social function for the authors rights}

\section{Abstract}

The social function has had multiple uses in private property law. Expropriation, easements or forfeiture are just some of the specific ways in which it becomes operational. We can infer, then, that more than a specific definition, it is a core idea that not having original content serves and has served as a tool for the realization of human values such as equality and solidarity. In copyright law there are readings and uses of social function that have not, however, met the specific forms of tangible ownership. Despite this, it has been implicit - and in some cases explicit - to the center of the modern critique of the institution. Through a critical approach, this paper presents the readings of the social function in copyright law and proposes, given the interpretative potential of this powerful idea, one possible reading.

Key words: intellectual property, social function, authors rights, expropriation, limitations and exceptions, public domain, solidarity, education.

\section{A função social do direito de autor}

\section{Resumo}

A função social tem tido múltiplos usos no direito de propriedade privada. A expropriação, servidão ou extinção de domínio são só algumas das formas concretas em que se faz operativa. Podemos inferir então, que mais que uma definição específica é uma ideia força que ao não ter um conteúdo único serve e tem servido como ferramenta para a concreção de valores humanos como a igualdade e a solidariedade. No direito de autor existem leituras e usos da função social que, no entanto, não têm conhecido as formas concretas da propriedade sobre tangíveis. Apesar disto, tem estado implícita - e em alguns casos explícita - no centro da crítica moderna à instituição. Mediante um enfoque crítico, este texto apresenta essas leituras da função social no direito de autor e propõe, dada a possibilidade interpretativa desta ideia força, uma possível leitura.

Palavras-chave: propriedade intelectual, função social, direito de autor, expropriação, limitações e exceções, domínio público, solidariedade, educação. 


\title{
La función social del derecho de autor
}

\author{
Julio César Padilla Herrera**
}

\section{SUMARIO}

Introducción - A. Estrategia metodológica - I. EL DERECHO DE AUTOR COMO DISEÑO LEGAL TRANSFRONTERIZO - II. LECTURAS DE LA FUNCIÓN SOCIAL EN EL DERECHO DE AUTOR - A. Lecturas reduccionistas - B. Lecturas marginales C. Lecturas huérfanas - III. CONCLUSIONES - Referencias.

* Cómo citar este artículo: Padilla Herrera, J. C. (Diciembre, 2015). La función social del derecho de autor. Revista de Derecho, Comunicaciones y Nuevas Tecnologías, 14. Universidad de los Andes (Colombia).

Este documento parte de la tesis presentada para optar al título de maestro (LL.M.). Dedico estas líneas a Lía Garzón.

** Maestro en Derecho (LL.M.) de la Universidad de los Andes, abogado y profesor de la Universidad Católica y la Universidad Militar. Curso de perfeccionamiento en Teoría de la Propiedad Intelectual en la Facultad Latinoamericana de Ciencias Sociales (FLAcso). Correo electrónico: jcpadilla@ucatolica. edu.co y padillaypadilla@gmail.com. 
Introducción

"Recordar que la propiedad está al servicio de valores humanos para las personas (...) como miembros de comunidades, ofrece esperanza de (...) conseguir una mayor igualdad social y económica en la región (...) un mayor orden y estabilidad sociales, económicos y políticos."

Colin Crawford

La cultura y la educación son legítimas aspiraciones en cualquier sociedad con un Estado democrático y constitucional. Ambos conceptos, quizá bastante amplios, han sido usados por movimientos sociales modernos para la defensa de nuevas causas. Desde esa defensa, se ha instaurado un ataque a la institución jurídica que llamamos derecho de autor. Esta última, se la considera una barrera para el acceso a la educación y la cultura, pensadas ambas como formas de información disponibles, fundamentalmente, en la Internet.

Este discurso de la crítica al derecho de autor propone una pregunta regular: ¿Es una barrera para el acceso a la información? Aparentemente la respuesta es no, pero si consideramos, de un lado, la Internet como un escenario de disponibilidad gratuita de bienes y servicios, y de otro, el derecho de autor como un sistema de derechos exclusivos y excluyentes que prohíbe la utilización de ciertos libros, fotografías, pinturas en esa misma red, la pregunta adquiere un nivel de pertinencia ineludible tanto para el defensor de la cultura y la educación como para el del derecho de autor.
Ahora bien, el problema ha sido abordado y, de hecho, la pregunta ha tenido respuesta dependiendo de quién la formule. Quienes responden: no, el derecho de autor no es una barrera para el acceso a la información, sino que promueve dicho acceso, suelen ser sus defensores (reaccionarios), que podría decir, tienen un punto de vista estático frente a la problemática. Los otros (internautas), en cambio, lo afirman; estos suelen ser ciudadanos virtualmente activos que infortunadamente sobrevaloran las virtudes de Internet, como un canal donde se depositan cultura y educación.

Una revisión de la literatura me ha permitido entrever con cierta claridad tanto la pregunta como el conflicto entre reaccionarios e internautas, esto, en parte, es lo que motiva este trabajo. Sin embargo, no pretendo responderla encontrando una posición entre alguno de los dos sujetos; por el contrario, indago otros asuntos que este debate/tensión/disputa ha dejado por fuera.

Estos asuntos son: ¿Existe alguna razón por la cual necesitamos en esta modernidad una institución como el derecho de autor?, ¿Requiere esta particular forma de propiedad una variación que le permita adaptarse al ambiente moderno de creación y transformación de los bienes que protege?, ¿Existen mecanismos de contención o de adaptación implícita en el derecho de autor, que le permitan mantenerse como sistema protector de intereses, pero compatible con la aspiración de una sociedad con mayor nivel de acceso a obras consideradas herramientas en pro de la cultura y la educación? Estos interro- 
gantes serán los que intentaré responder desde el punto transversal en que se ubican: Ios límites al derecho de autor.

En el derecho de autor existe un sujeto creador que se hace a unos derechos por virtud de cierto esfuerzo. Lo que crea es la obra; en algunas ocasiones esta representa un alto valor social y cultural, que se pone a disposición del público y requiere ser protegida para evitar su apropiación/explotación/uso en contra de los intereses del titular de derechos patrimoniales. La obra, desde el derecho de autor, es un bien que contiene la forma de expresión de las ideas del autor, que puede ser un libro pero también una pintura o una película, entre otras. ${ }^{1}$

De otro lado, leer, contemplar o escuchar son actos de uso del bien, que son legales solo si: 1) se adquiere el bien mediante la compra legal, 2) el autor lo autoriza directa o indirectamente mediante licencias o cesiones, y 3) a pesar de que el autor no lo autoriza el uso no va en contra de los intereses de este y la ley lo permite, como en el caso de las excepciones y limitaciones al derecho de autor. Adicionalmente, existe otro acto de uso, que es aquel realizado cuando la

1 Según el Convenio de Berna para la Protección de Obras Literarias y Artísticas (1886), artículo 2: "1) Los términos 'obras literarias y artísticas' comprenden todas las producciones en el campo literario, científico y artístico, cualquiera que sea el modo o forma de expresión, tales como los libros, folletos y otros escritos; las conferencias, alocuciones, sermones y otras obras de la misma naturaleza; las obras dramáticas o dramático-musicales; las obras coreográficas y las pantomimas; las composiciones musicales con o sin letra; las obras cinematográficas, a las cuales se asimilan las obras expresadas por procedimiento análogo a la cinematografía; las obras de dibujo, pintura, arquitectura, escultura, grabado, litografía; las obras fotográficas a las cuales se asimilan las expresadas por procedimiento análogo a la fotografía; las obras de artes aplicadas; las ilustraciones, mapas, planos, croquis y obras plásticas relativos a la geografía, a la topografía, a la arquitectura o a las ciencias." [Cursivas añadidas]. Esta es una lista enunciativa. obra no tiene titular de derechos económicos, por haber fenecido el tiempo de protección legal o estar en el dominio público. Estos dos últimos constituyen límites del derecho de autor, en tanto que condicionan la potestad del propietario sobre la obra.

Ahora, la obra como bien es propiedad privada. Esta última, entendida como un derecho real sobre una cosa. Por supuesto, el propietario tiene el goce y disposición, luego podrá aprovechar o explotar la cosa como considere, hasta el límite que impone la ley o el derecho de otros; por el hecho de que creó la obra o la transferencia de derechos patrimoniales el ejercicio de sus prerrogativas se encuentra legalmente justificado.

Pero hay algo en lo anterior que no ha tenido un tratamiento amplio. La propiedad privada ya no es únicamente un derecho subjetivo de naturaleza absoluta. En Colombia, según la Constitución Política de 1991, la propiedad es función social y su comprensión depende de la propiedad de que se trate (Alviar y Villegas, 2012; Bonilla, 2013; Coral y Batista, 2010).

Así pues, la función social de la propiedad es una idea fuerza en el derecho civil clásico y moderno. En lo que respecta a derechos sobre bienes materiales, se resume en la siguiente versión común: 1) el goce y disfrute de un bien no son potestades absolutas, 2) un Estado social de derecho tiene como uno de sus principios cardinales el de la solidaridad, 3) en virtud de la solidaridad es posible restringir "el goce y disfrute", en beneficio del interés general, cediendo ante las obligaciones con la comunidad o el 
Estado y 4) la expropiación es una de varias formas concretas ${ }^{2}$ de función social de la propiedad privada. Pero esto es solo lo que respecta a la propiedad sobre bienes materiales. Luego, la pregunta es: ¿Cuál es la función social del derecho de autor particularmente?

Aunque no está lejos de la versión común, a diferencia de la propiedad privada donde la doctrina, la jurisprudencia, la literatura sobre la materia y los agentes han señalado cómo debe entenderse 0 , por lo menos, cuál es el marco comprensivo de esa idea fuerza, en el derecho de autor ninguna de esas fuentes lo ha hecho con tanta articulación. Entonces, ¿cómo ha sido leída la función social en el derecho de autor? Esa es la pregunta central de este texto.

Para responderla presento las versiones en la categoría lectura que servirán para comprender el tema específico con fines descriptivo-analíticos, y sin que por ello se abarquen todos los puntos en los que se supone que el fenómeno tiene lugar (Weber, 1973). De tal forma, en materia de derecho de autor las lecturas que propongo son reduccionistas, marginales y huérfanas $^{3}$ de lo que se entiende por función social. En la segunda parte, las presento articulando

2 Como tal no se puede decir que existe tan solo una forma, por ello lo que se tiene son ciertos criterios aproximativos vinculados a los principios constitucionales. Además, la Corte Constitucional lo que ha señalado es que existen varias acciones específicas que pueden imponer al propietario como sujeto obligado por la función social. Desde la construcción de una línea jurisprudencial, Guío Camargo (2009, pág. 55) señala las siguientes: “a) Supresión de ciertas facultades del propietario, b) Ejercicio condicionado de las facultades legales del propietario y c) Ejercicio obligado de algunos deberes (Corte Constitucional, T-427 1998)." Esto último es particularmente relevante como argumentaré después.

3 En el capítulo respectivo expondré por qué las denomino así. la discusión en que tienen lugar y explicando por qué las denomino así. Mientras tanto, estas lecturas me permitirán mostrar las formas concretas en que se ha aplicado la función social y su interacción con la crítica moderna al derecho de autor.

\section{A. Estrategia metodológica}

Esta investigación de la función social en el derecho de autor será abordada desde una perspectiva crítica, en razón a que presenta un análisis renovado -aunque alienta el reconocimiento de derecho de autor, así como la explotación de estos- que pone atención fundamentalmente en el límite del ejercicio de los derechos de autor, en cuanto a sus efectos frente a la cultura y la educación en un Estado democrático y constitucional pero en vías de desarrollo. ${ }^{4}$

Por lo anterior, este texto no hace un análisis normativo-dogmático, esto es, no busca enseñar y potenciar la teorización (función sistematizadora), o sugerir soluciones mediante comentarios a leyes o sentencias (función de lege data) ni modificar el material jurídico (función de lege ferenda) según mis valoraciones (Cour-

4 Reconozco que la expresión es incorrecta por el falso desarrollismo evolucionista que oculta. Sin embargo es la que utilizan todos los informes de la Organización Mundial de la Propiedad Intelectual y la mayoría de autores en esta materia. Acorde con Lamprea (2008), la expresión correcta es países del sur global, donde un porcentaje mayoritario de la población vive en circunstancias de pobreza, con ingresos bajos, vivienda deficiente, acceso a servicios precario, pocas oportunidades educativas, altas tasas de mortalidad infantil, expectativas de vida baja, altas tasas de desempleo, escasez de recursos, la agricultura tiene un tratamiento preferente en comparación con otros sectores de la industria, la manufactura o la prestación de servicios; hay una alta dependencia a la exportación de materias primas, así como a la política internacional y las relaciones que fijan los países del noratlántico. 
tis, 2003, 2006). Sin perjuicio de los trabajos que se realizan en derecho privado en general y sobre derecho de autor particularmente, cuyo método suele ser de este tipo, prefiero abordar el problema desde una aproximación crítica.

Aclaro que la función social del derecho de autor $^{5}$ no es un objeto de investigación recurrente en los estudios interdisciplinarios críticos, ${ }^{6}$ pero sí tiene un impacto social decisivo como anota Colin Crawford (2013, pág. 146), y en esa medida la caja de herramientas que brinda este enfoque es compatible con el trabajo que presento. En ese sentido, las fuentes de este texto son libros especializados, en algunos casos de autores locales, artículos de revistas indexadas, papers, documentos de sitios web y también observaciones verificables realizadas a partir de la asistencia a algunos eventos oficiales sobre derecho de autor y mi experiencia como profesor e investigador en dos universidades. Aun así, esto no significa que descarte las normas y sentencias como elementos dentro de mi inves-

$5 \quad$ El tema de la función social es relevante pues se relaciona de forma directa con la idea de límites a las facultades de los titulares de derechos de propiedad intelectual y ha sido estudiado especialmente en Brasil, aunque fundamentalmente en materia de patentes. Algunos trabajos que recomiendo son: Heloísa Gomes Medeiros, especialmente su tesis de maestría que está disponible en: https:// repositorio.ufsc.br/bitstream/handle/123456789/94771/295690. pdf?sequence=1; Luciane Klein Vieira en un artículo donde narra la experiencia brasilera en materia de licencias obligatorias, disponible en: http://dei.itam.mx/archivos/articulo2/Klein.pdf; y Alberto Cerda Silva, quien se ocupa de este mismo tema en Chile, en un artículo disponible en: http://www.scielo.cl/scielo.php?script=sci_arttext\&pid $=$ S0718-00122010000200011.

García y Rodríguez (2003, pág. 16) afirman que "dada la gran variedad de fenómenos jurídicos en la región, la reflexión colectiva sobre los mismos es viable sólo si comienza por tratar un número limitado de temas que faciliten el diálogo entre los investigadores de la región, por ser comunes a la mayoría de los países latinoamericanos, tener un impacto social decisivo o ser objeto recurrente de los estudios disponibles." tigación, pero no desarrollo con estas una labor de ordenación y descripción.

Entonces, el enfoque crítico que uso, quiere decir que mi trabajo tiene en cuenta el contexto social de los asuntos que analizo, las deficiencias y contradicciones de algunas descripciones del derecho en contraste con su realidad, y algunas fuentes de diversas disciplinas no jurídicas (Frankenberg, 2011; García y Rodríguez, 2003) para luego presentar una reflexión crítica propia sobre el problema.

Ahora bien, el texto está construido de la siguiente forma: sugiero que el derecho de autor es un diseño legal transfronterizo y en tal sentido esta condicionado para ser repensado localmente. En la segunda parte, expongo las lecturas de la función social en el derecho de autor a partir de los discursos, ideas y posiciones de ciertos actores en esta materia. Finalmente, presento conclusiones que vinculan los elementos argumentativos que desarrollo en el texto y que en términos generales hacen ver que el derecho de autor es un diseño legal transfronterizo bastante sólido, pero que en el contexto local aún no dialoga con su función social.

\section{EL DERECHO DE AUTOR COMO DISEÑO LEGAL TRANSFRONTERIZO}

El derecho de autor es un diseño legal transfronterizo (López, Ángel, Posada y Moncada, 2013, pág. 25) en la medida que cambia dependiendo de la suscripción de tratados de libre comercio y se ha formado a partir de convenios interna- 
cionales y uniones de carácter regional. Así, en el Convenio de Berna de 1886; el Convenio de Roma de 1961; los tratados de la Organización Mundial de la Propiedad Intelectual (OMPI) sobre Derecho de Autor (TODA/WCT) de 1996, sobre interpretación o ejecución y fonogramas (TOIEF/WPPT) de 1996, el Tratado de Beijing sobre Interpretaciones y Ejecuciones Audiovisuales de 2012, el Tratado de Marrakech para facilitar el acceso a las obras publicadas a las personas ciegas, con discapacidad visual o con otras dificultades para acceder al texto impreso, de 2013; y la Decisión Andina 351, están los contenidos mínimos del derecho de autor. El primer efecto: cualquier regulación local debe atender a esa estandarización mundial de reglas que, además, refuerzan los Acuerdos sobre los Aspectos de los Derechos de Propiedad Intelectual relacionados con el Comercio -ADPIC- de la Organización Mundial del Comercio (омс) que, como señala Bonilla (2009, pág. 23), es un agente exportador de derecho.

En ese sentido, países como Colombia se encuentran con una aparente imposibilidad de regulación legal interna sobre derecho de autor. Las leyes locales suelen trasponer lo que se ratifica en aquellos tratados y convenios, la mayoría de veces sin construcciones legales autónomas. Para profundizar sobre esto, es necesario analizar la formación del derecho de autor evidenciando el carácter gremial, extralocal y transfronterizo que ha tenido y cómo esto ha sido estructurante en su compresión y operatividad.

En primer lugar, el Estatuto de la Reina Ana, una ley británica de hace más de trescientos años (1709), fue la primera que lo reguló. Esta conce- dió privilegios a editores por cierto tiempo, (posteriormente a los autores), promoviendo según el documento de la ompI (s. f. pág. 2), "la competencia en el círculo de los editores, restringiendo los monopolios y reconociendo al autor como el titular del derecho a autorizar la copia de la obra". Este Estatuto ha brindado algunos de los contenidos mínimos que comparten el copyright (derecho de autor) $^{7}$ continental, uno de ellos: que el derecho de autor consiste en autorizar y prohibir.

Siguiendo a Zukerfeld (2010), Sádaba (2007) y Padilla (2013), aunque el autor cobra relevancia sobre todo después de la invención de la imprenta -siglo XV, año 1440- fue el sector de los libreros el que inició la ardua labor de: a) la institucionalización de la actividad creativa, bajo

7 Las diferencias ocurren en los contextos reales donde tiene lugar el derecho de autor. En EE. UU. las industrias están fortalecidas, entre otras cosas y como sugiere Joel R. Paul (2006), por las políticas públicas de apoyo y subsidio a muchos sectores; existen muchos abogados expertos en propiedad intelectual que se dedican al litigio especializado; el sector académico se hace cargo de lo que le toca: escribir y debatir la teoría, operatividad, eficacia y eficiencia del copyright, luego podría decirse que hay varias direcciones de análisis. En Colombia, mucho de lo que existe es unilineal y homogéneo. Pero así dispuesta, la comparación parece reduccionista y odiosa. Así que, aclaro, lo que quiero decir no es que allá sean mejores, sino que la diferencia reside más en la forma como ellos han entendido y operado el sistema del copyright sobre la base de valores de utilidad y eficiencia, las múltiples voces (ej. Lawrence Lessig) que discuten y cómo nosotros lo hemos hecho: derecho a prohibir, autorizar, permitir, recaudar, es decir, un derecho con una lectura y operatividad verbosa, donde el sector académico más representativo realiza fundamentalmente manuales, y los agentes con voz suelen ser abogados que defienden los mismos intereses de los gremios, que están protegidos en las leyes, esto es, que el sector de la crítica se reduce a nuevos actores sin voz ni capital social suficiente como para equilibrar las posibles discusiones, proponiendo formas diferentes de entender y operar el derecho de autor. Por otro lado, suele distinguirse entre copyright - C - y derecho de autor —DA- enfatizando en que las finalidades de ambos son divergentes. El (c) es proempresa y el DA proautor. No obstante, ninguno de los dos sistemas funciona si los agentes no interactúan entre ellos y si el intercambio de obras no es sólido. Un sistema podría ser garantista para el autor (DA), pero si este último desconoce cómo podría gestionar económicamente su obra estaría en una situación de vulnerabilidad igual a la que existiría en ausencia de las garantías. 
la forma de un estatuto jurídico que reconoce el proceso de creación y la 'necesidad de difusión' de los contenidos de la obra y b) la estructuración de las herramientas necesarias en las piezas jurídicas -leyes o convenios como el acta veneciana de 1474, y años después el Convenio de Berna- para la defensa de la actividad ilícita de los "corsarios" de entonces y de los "piratas" de ahora. También Merges y Ginsburg (2004), Cavalli (2006) y Sádaba (2007) señalan que la Société des Gens de Lettres (SDG), liderada y creada por Víctor Hugo, con miembros como Alejandro Dumas y Honoré de Balzac, fue la que promovió la creación de un sistema de protección universal sobre las obras literarias, que luego se convertiría en el primer convenio de derecho de autor, cuya vocación es la protección universal de obras originales. La necesidad de estos y otros actores de regular este escenario productivo surgió también por factores económicos que estaban afectando a editores e impresores.

Los franceses y los belgas, indica György Boytha (citado en Uchtenhagen, 1998, pág. 19), tuvieron antes de la adopción del Convenio de Berna muchas dificultades con la impresión de libros. Mientras los franceses firmaban contratos con sus autores, imprimían libros y obtenían ganancias, los belgas, gracias al terreno lingüístico común que compartían con Francia, tomaban las obras de aquellos y las reimprimían ganando también pero sin autorización de los editores franceses (Lipszyc, Villalba y Uchtenhagen, 1998, pág. 79).

El malestar de los franceses y de otros países cuya situación era similar exigió a los gremios el establecimiento del emergente derecho de autor. Ahora bien, estos libreros, editores y autores legitimaron en lo institucional la configuración del derecho de autor continental (droit d'auteur) y la primera gran herramienta diseñada por la industria creativa más importante (la de los libros) de aquel momento, que es el Convenio europeo de Berna.

Inicialmente en América la recepción del Convenio de Berna no fue pasiva, por razones políticas superficialmente evidentes. De un lado, la aun reciente latinoamericana de España y de Portugal y el consecuente rechazo de cualquier “injerencia europea” en los procesos nacientes (y conflictivos) de construcción política nacional. De otro, que el Convenio de Berna tuviese una cláusula colonial generó mayor resistencia a la adopción de la protección internacional europea. Ahora, la misma unión forzada entre franceses y belgas se dio entre Europa y América. El "terreno lingüístico" que comparten los países que hablan en español y portugués generó la misma preocupación que cuando se estaba gestando el Convenio de Berna. No obstante, los libreros y autores necesitaban que la mayor cantidad de países adoptaran el acuerdo, de manera que fuese más fácil para ellos exigir el

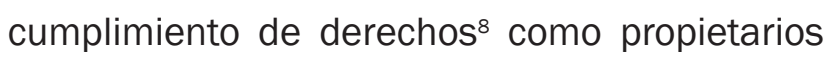
(titulares exclusivos) de sus obras. Ahora bien, luego de un proceso de resistencia breve y que en cualquier caso América no descuidó, ${ }^{9}$ los liEse cumplimiento se traduce claro en la remuneración por la reproducción o uso de la obra. Jhonny Antonio Pabón (2011) hace una historia de la propiedad intelectual en Colombia. Parte del supuesto metodológico de la evolución de la institución. Así las cosas, acorde con el autor, tenemos 
breros europeos lograron que una gran cantidad de países americanos suscribieran el acuerdo (Lipszyc et al., 1998).

Esta fase de los libreros ${ }^{10}$ marca notablemente el Convenio de Berna (1886) y el diseño legal general pensado para un sujeto ideal: el escritor. Es decir, se asienta desde la lógica productiva de libros que son obras de arte cualitativamente distintas al arte plástico, la música o la obra audiovisual. No obstante, todas hacen parte de la categoría de obra del derecho legislado que, en el ámbito local, además se les da el mismo tratamiento en cuanto a requisitos de protección y duración de derechos. Uno de los problemas de leer el DA como un derecho de libros, es que las excepciones y limitaciones ${ }^{11}$ son diferentes en cada clase de obra. Las relativas al uso de obras por parte de personas en condición de discapacidad

un periodo antiguo donde se concedían privilegios de explotación de forma perpetua que podían heredarse, como el conferido a César Conto y Emiliano Izasa por la cartilla Nuevo Método para enseñar a leer, de 31 de mayo de 1834 (pág. 211), y un periodo contemporáneo donde tenemos una propiedad intelectual cuyos derechos son temporales y no requieren registro para que existan.

10 Siguiendo a Sádaba (2007), podemos decir que el derecho de autor se formó a través de las siguientes fases: 1) la de los libreros, editores y periodistas, 2) la de remuneración para los escritores, 3) aquella en que se reconocen derechos de autor como naturales y necesarios para la remuneración por la creación realizada, y 4) la de intercambios comerciales mundiales. Las anteriores etapas las denomina: inglesa, francesa, norteamericana y global.

11 Se trata de un listado de usos implícitamente autorizados y taxativamente dispuestos en la ley, por ejemplo, citar una obra es un derecho a favor de quien requiere citar y que el autor de una obra publicada no puede impedir. El copyright no tiene este catálogo sino la doctrina del Fair Use que consiste, siguiendo a Bercovitz (2009), en: 1. El destino no lucrativo, 2. La naturaleza de la obra protegida, 3. El volumen y la importancia de la parte utilizada con relación al conjunto de la obra protegida, 4. La influencia del uso sobre el mercado potencial de la obra protegida o sobre su valor." Esta sí es una diferencia estructurante entre copyright y DA continental (Rodríguez, 2004). están evidentemente dirigidas a obras escritas, ${ }^{12}$ en cambio, las demás parecen cobijadas por una serie de interpretaciones extensivas.

A pesar de esto último, el diseño de normas y esquemas de acción depende de la dinámica de las industrias de producción y comercialización de productos culturales. En Colombia, debido a dos factores, esto es distinto. De un lado, como país receptor, el diseño local solo puede ocurrir en el escenario de las excepciones y las medidas para países en desarrollo. De otro lado, el lento desarrollo de las industrias culturales locales, que no tienen mayor relevancia en términos del diseño en comparación con las extranjeras. Quiere decir lo anterior que las industrias innovan y diseñan la forma en que el DA funciona, pero únicamente en países con un sector industrial fuerte y dinámico, los demás reciben y adaptan el diseño transliterando las disposiciones de los tratados y acuerdos comerciales respectivos.

Este carácter del DA como diseño transfronterizo, además, traza implícitamente la forma en que se discute sobre la materia y determina a los actores, prácticas y discursos. De esa forma, al derecho de autor se lo considera cierto tipo de conocimiento que los expertos no localizan, ${ }^{13}$

12 Según el tratado de Marrakech, "para facilitar el acceso a las obras publicadas a las personas ciegas, con discapacidad visual o con otras dificultades para acceder al texto impreso" (artículo 2, literal a). Por "obras" se entenderán las obras literarias y artísticas en el sentido del artículo 2.1) del Convenio de Berna para la Protección de las Obras Literarias y Artísticas, en forma de texto, notación y/o ilustraciones conexas con independencia de que hayan sido publicadas o puestas a disposición del público por cualquier medio.

13 Me refiero a que no se analiza desde los escenarios concretos y las necesidades contextuales; el derecho de autor se lee como un elemento que proviene de una familia jurídica con una fundamentación 
simplemente describen y operan, de allí que los agentes -con voz- suelan ser consultores, litigantes y operadores institucionales. En este punto hago alusión al Diagnóstico del derecho de autor en América Latina, elaborado por un grupo de autores coordinados por el CERLALC ${ }^{14}$ (Zapata et al., 2007, pág. 135):

Uno de los problemas capitales, no sólo en América Latina sino también, al parecer, en otras regionales del mundo es la ausencia de la enseñanza del derecho de autor (...) en la carrera de derecho (y, eventualmente, en otras carreras relacionadas con la disciplina), no obstante que de allí saldrán los futuros jueces, fiscales, directores y funcionarios de las oficinas nacionales de derecho de autor $y$, en fin, los abogados consultores y litigantes capacitados para asesorar o representar a los titulares de derechos intelectuales y a los usuarios de las obras y demás prestaciones protegidas. [Cursivas añadidas].

Lo anterior sugiere que el derecho de autor es un escenario claro y perfectamente operativo. Por eso, el problema importante es el desconocimiento, y la solución: la enseñanza en pro de agentes formados desde, por y para el DA. Luego, el cumplimiento ${ }^{15}$ y el respeto a los derechos de autor se convierten en el punto de partida

extralocal e indiscutible.

14 Centro Regional para el Fomento del Libro en América Latina y el Caribe.

15 Pronto se ha convertido en cotidiano lo que Diego López (2014, pág. 49) Ilama la cultura del cumplimiento de normas: "En concreto, el movimiento en favor de una 'cultura de la legalidad' identifica que la dimensión fundamental de la vida social que hay que reforzar es el nivel de cumplimiento voluntario, por parte de los ciudadanos, de las reglas institucionales y compartidas de convivencia." del análisis del DA localmente, debido a la claridad del marco legal y la fundamentación del DA que supone el diagnóstico.

Lejos de ello, es precisamente esta suposición (que conviene aclarar, es falsa) la que vuelve hermética la discusión sobre DA local: 1) Al ser más relevantes localmente los abogados/consultores, las preguntas posibles sobre DA son las que se presentan en la práctica o ejercicio de estos; las motivaciones de quienes discuten, son los obstáculos que se encuentran para la aplicación de contenidos normativos, y en general la investigación se dirige localmente hacia la solución de los problemas operativos del DA, como ¿qué implicaciones tiene un tratado teniendo en cuenta la tradición jurídica continental?, ¿Internet es una herramienta en contra del DA?, ¿cómo puede explotarse más la obra según el marco legal? Entonces, la bibliografía local sobre DA y la propiedad intelectual (PI) en general trabajan la materia como si fuese un asunto obvio, reiterativo y circular, insistiendo en descripciones lineales contenidas bajo la forma clásica del manual, que con definiciones y afirmaciones parafraseadas, tomadas directamente de los tratados y convenios internacionales, presentan información pero no construyen conocimiento. EI DA, según una gran parte de los autores locales, la mayoría de veces con las características del diagnóstico del CERLALC, es un asunto básico. Las reflexiones críticas o las opiniones disidentes se convierten en indeseables, en contextos donde los que practican ${ }^{16}$ nacionales de derecho de autor" (Zapata et al., 2007, pág. 135). 
son, según el diagnóstico, los únicos actores necesarios.

La función social, por otro lado, es un dispositivo abierto a interpretaciones con un marco teórico, ideológico y político que no es estático. Esta condición lejos de ser problemática, permite analizar el derecho de autor sin la descripción plana de los manuales y favorece una investigación menos dócil sobre la materia.

Lo anterior porque aun como diseño transfronterizo, el DA contiene una función social cuya ventaja reside en que escapa a la adherencia estrictamente normativa y por ende promueve la reflexión crítica. Ahora, la función social del $\mathrm{DA}^{17}$ no tiene la misma relevancia que aquella propia de la propiedad privada sobre tangibles. La articulación bibliográfica que existe en la segunda no es la misma que la primera; pero ello no ha sido óbice para que no esté presente tanto en las voces de los agentes que practican, como en la crítica moderna al derecho de autor.

\section{LECTURAS DE LA FUNCIÓN SOCIAL EN EL DERECHO DE AUTOR}

La función social actúa como idea-fuerza, pues permite renovar la forma en que se ha entendido el derecho de propiedad privada. Las múltiples interpretaciones que se formulan no tienen que ver con relativismos, sino con la posibilidad que el mismo concepto brinda. Así, Bonilla (2013,

17 Que es una forma de propiedad, consistente en el derecho exclusivo y excluyente a explotar económicamente durante el tiempo legal la obra que se crea o sobre la que se obtienen derechos patrimoniales. pág. 11) nos señala varias de ellas, con énfasis en la concepción liberal clásica; esta advierte que la propiedad es un derecho-deber del individuo, en el que el Estado no puede intervenir, a menos de que exista un cierto interés público $y$, en cualquier caso, el propietario tiene tanto el poder de excluir a otros como el de sacar provecho obteniendo los frutos que se siguen de esto. Esta versión liberal clásica es la que se tiene en el derecho de autor en Colombia.

La función social, según algunas sentencias de la Corte Constitucional y autores del campo del DA, son las excepciones y limitaciones al derecho de autor (en adelante exc. li.) y el dominio público. Ambos son límites externos que se imponen al legítimo propietario, en beneficio de la sociedad, sin que pueda reclamar alguna vulneración por ello. Esta manera de entender, interpretar o leer la función social en este derecho es reduccionista, en la medida que lo presenta de forma acotada como un derecho subjetivo/ absoluto con algunas limitaciones que, sin embargo, no pueden afectar al titular de derechos.

En la primera parte me ocupo de algunos de los que la representan, adelantando que aquí ubico a: Zapata López (2008), Rodríguez (2004), Torres Cadena (2001), Monroy (2009), la Corte Constitucional y entidades privadas como el Centro Colombiano del Derecho de Autor, que es un grupo de abogados consultores expertos en derecho de autor.

Por otra parte, las lecturas marginales, entre las que incluyo la de la mayoría de la crítica moderna e hipermoderna al derecho de autor, sugieren mucho más de lo que dicen. Estas lec- 
turas se mueven en extremos: la erradicación/ eliminación de la institución y su posterior refundación con la consigna "el derecho de autor no debe existir por ser una barrera injustificada para el acceso a la educación y la cultura" y debido a su condición obsoleta frente al intercambio y producción actual de contenidos e información; en reemplazo, proponen conectar a los individuos buscando que el conocimiento sea de todos, aunque es una agenda que opera fundamentalmente mediante la cooperación virtual comunitaria.

Son marginales en la medida que plantean una crítica (en múltiples ocasiones críptica) desarticulada pero legítima en cualquier discusión sobre un fenómeno sociojurídico, en este caso, el acceso a la educación y cultura que el sistema normativo protege/garantiza y a la vez permite que se restrinja. Este carácter marginal se lo da también el lugar en que se encuentran en relación con los lectores reduccionistas que, no obstante, tienen más autoridad ${ }^{18}$ en el campo del derecho de autor local. Los textos y posiciones de las lecturas marginales son muchos y provienen de distintos contextos, pues se dan en la coyuntura de la convergencia digital, que es el lugar por antonomasia donde están fortalecidas, donde hay una plétora de voces unidas en grupos virtuales. En la segunda parte defino en qué consisten, por ahora estas lecturas están representadas por los siguientes: Lawrence Lessig, con la iniciativa de licencias Creative Com-

18 En el campo del derecho en que se discute sobre este tema, a algunos actores se los reconoce según su adherencia institucional: DNDA, CERLALC... etc. Es en este sentido que me refiero a la autoridad medible por su capacidad de acción. mons; James Boyle, con su propuesta del dominio público; Neil Weinstock Netanel y su idea del copyright para la formación de una sociedad civil; Julio Raffo, con el proyecto de fundación vía libre y algunos movimientos Ilamados ciberlibertarios, hacktivistas o activistas digitales como RedPaTodos, Copyleft, Anonymus, la Fundación Karisma cuya representante local más visible es Carolina Botero ${ }^{19}$ y la ong Derechos Digitales.

Ahora bien, existe una disputa entre los lectores reduccionistas y los marginales. Aunque las implicaciones de la Internet en el DA son las que permiten la posibilidad de repensarlo y revisitar las bases sobre las cuales solía ser una institución plenamente justificada, los reduccionistas no dialogan con lo que sugieren los marginales viendo sus posiciones como ilegítimas, por ello estos agentes son reaccionarios.

Por último, las lecturas huérfanas, aunque no tienen autoridad no son marginales, tienen un argumento potente: el DA es función social, por lo cual aunque es legítimo, además de garantista para la protección de intereses particulares como los de gremios y autores, se muestra completamente ineficaz en cuanto a la promoción de la participación en la vida cultural de aquellos no propietarios. Aquí no hay una posición de readaptación a lo digital ni de erradicación de la institución, por el contrario, complementan el argumento que las lecturas reduccionistas no profundizan, sugiriendo que la base del derecho de autor es la función social y los derechos fun-

19 Abogada, columnista regular e invitada a la mayoría de discusiones sobre el derecho de autor en Internet.| 
damentales. En ese sentido, se las puede ubicar en el liberalismo igualitario. Al finalizar, me ocupo de estas lecturas. A quienes ubico aquí son: Paul L. C. Torremans y Christophe Geiger.

Propongo la expresión lecturas reduccionistas, marginales y huérfanas, para organizar las posiciones, modelos e ideas que determinado grupo de actores tienen para entender los límites al derecho de autor y con estos su función social inherente.

Para puntualizar, el argumento de la función social que comparten estas lecturas está constituido por las siguientes dos premisas: i) como derecho de propiedad se encuentra limitado por un interés mayor que el del titular de derechos, por lo cual ii) su finalidad además de proteger, (interés particular), es promover el acceso a la información, la educación y la cultura (interés general). De otro lado, la pertinencia de los autores que cito queda sustentada en las siguientes razones: en primer lugar, la mayoría tienen impacto en las redes o campos donde se discute acerca del derecho de autor (las lecturas reduccionistas), otros fueron los precursores de la crítica moderna e hipermoderna al derecho de autor (lecturas marginales) y los últimos porque tienen argumentos sólidos en otros contextos, aunque la circulación y articulación de sus posiciones no tengan autoridad en el DA local (lecturas huérfanas).

\section{A. Lecturas reduccionistas}

Presentan el derecho de autor ampliando los enunciados de leyes y convenios que regulan la materia. En este sentido (Zapata, 2008; Rodríguez, 2004; Torres, 2001; Monroy, 2009) señalan tres formas clásicas de función social.

La primera de ellas consiste en que luego de ochenta años después de la muerte del autor, la obra pasa al dominio público. Al no existir ningún titular de derechos patrimoniales por no estar vigente el derecho, cualquiera puede usar o transformar la obra. Que el tiempo no esté justificado, denota arbitrariedad en el sistema normativo. Aunque los autores previamente citados sugieren que una vez concluye ese término es posible que no haya ningún reclamante $\mathrm{y}$, por ende, pueda usarse la obra, y también que ese cálculo permite a los herederos explotarla económicamente (Lipszyc, 2003; Dusollier, 2010).

¿Si la función social se entiende como la imposición de obligaciones en beneficio de la sociedad al propietario, cuál es la obligación cuando el derecho ya no existe y la obra quizá ya no tenga tanto valor cultural? Que no sea perpetuo sería la respuesta de esta lectura. La obligación, precisamente, reside en que aunque es propiedad, no es perpetua como lo es en su forma clásica (sobre bienes materiales), por lo cual la función social es la imposición del dominio público. Pero la respuesta no dice nada en relación con lo que sí es: la ausencia (porque no hay reclamante) de derecho a autorizar o prohibir el uso de la obra. Por una parte, que el cálculo sea un estimado de ochenta años, quiere decir que con el paso del tiempo la obra no tendrá tanto valor económico/ cultural; luego será posible que el interés de los potenciales reclamantes también disminuya. Pero en el arte plástico algunas obras adquieren 
más valor con el paso del tiempo y el público que las consume es menor, en comparación con el lector.

Por otro lado, las obras musicales se consumen con más regularidad y se producen mucho más que las escritas; las primeras tienen múltiples formas de ser consumidas y varios canales de explotación, mientras que las últimas tienen un público más reducido y selectivo. Todo esto significa que el dominio público no puede ser igual en todas las circunstancias de producción de obras, pues hay más receptores y con ellos intereses sociales.

Además de lo anterior, el dominio público, que es un escenario donde las obras que se crearon no tienen titularidad patrimonial activa, donde cualquiera podría publicar, crear obras derivadas, subirlas a la nube o simplemente leerlas sin ninguna restricción, es la garantía siguiendo esta lectura de que se está promoviendo el acceso.

En Colombia, por ejemplo, las obras que están en el dominio público las custodia el Instituto Colombiano de Cultura, institución que ya no existe, y la que hace sus veces es el Ministerio de Cultura, que no tiene según sus normas de creación ninguna función relativa a este tema. Es decir, que para saber cuáles y cuántas son las obras que están en el dominio público en Colombia hay que hacer cálculos dependiendo del año de creación y de la ley que aplicaba en el momento en que se creó la obra. Este descuido institucional de la gestión del dominio público es otra de las debilidades del DA local que permite cuestionar las lecturas reduccionistas.
Es dable inferir que el dominio público es una obligación de las instituciones que promocionan el DA, que funciona como una garantía para los usuarios de obras como la titularidad para los autores; a pesar de esto las oficinas de derecho de autor tienen fundamentalmente la función notarial del registro de obras y suelen trabajar (sigo en el contexto local) con un presupuesto mínimo que reduce su margen de acción y capacidad de innovación frente -entre muchas cosas-al dominio público.

Otra forma de función social, según los reduccionistas, son las excepciones y limitaciones o licencias no voluntarias. Estas se circunscriben a casos taxativamente dispuestos en la ley, siempre que no se atente contra la normal explotación de la obra, y sin que se cause perjuicio injustificado a los legítimos intereses del titular (Ficsor, 2008). En el cuadro 1 se relacionan las más relevantes, conforme al marco legal local, y algunas observaciones. 
Cuadro 1. Observaciones globales a algunas limitaciones o excepciones al derecho de autor

\begin{tabular}{|c|c|c|}
\hline Exc.li & Cómo opera & Observaciones \\
\hline 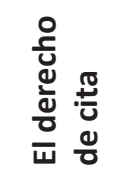 & $\begin{array}{l}\text { Usar el texto contenido en una obra en otro de } \\
\text { forma textual o paráfrasis, indicando siempre la } \\
\text { fuente y el nombre del autor. }\end{array}$ & $\begin{array}{l}\text { Funciona para obras escritas como libros, } \\
\text { artículos de revistas y similares. No obstante, una } \\
\text { interpretación extensiva de la ley podría extender } \\
\text { su operatividad a las demás obras. }\end{array}$ \\
\hline 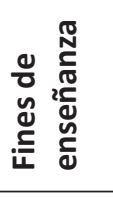 & $\begin{array}{l}\text { Usar una obra en instituciones de enseñanza, o } \\
\text { incluirla en otra con fines de enseñanza, educativos, } \\
\text { universitarios o de formación profesional, sin fines } \\
\text { de lucro, y citando (Ficsor, 2008). }\end{array}$ & \multirow{2}{*}{$\begin{array}{l}\text { Esta limitación evita el abuso del derecho del titular } \\
\text { haciendo imposible que exija el cumplimiento de } \\
\text { su derecho, en las circunstancias descritas. A pesar } \\
\text { de todo, deben pagarse derechos reprográficos o } \\
\text { licencias a las sociedades de gestión de las obras } \\
\text { en las universidades, colegios u otros sin importar } \\
\text { estas Exc.Li (Macías, 2006). }\end{array}$} \\
\hline 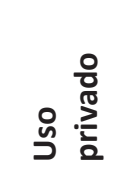 & $\begin{array}{l}\text { Puede reproducirse un solo ejemplar para uso } \\
\text { privado sin fines de lucro. }\end{array}$ & \\
\hline 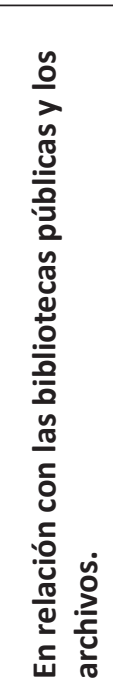 & $\begin{array}{l}\text { Las bibliotecas y archivos pueden reproducir para } \\
\text { uso exclusivo de sus lectores las obras solo: } \\
\text { Con fines de preservación o reemplazo de } \\
\text { copias deterioradas o perdidas, y siempre } \\
\text { que no existan en el mercado más copias. }\end{array}$ & $\begin{array}{l}\text { La forma en la que se piensa localmente el DA, } \\
\text { como dije antes, es como un derecho de libros. Por } \\
\text { eso, la ley colombiana menciona a los "lectores", } \\
\text { pero debe entenderse sus usuarios, siendo que no } \\
\text { todas las obras son escritas. } \\
\text { La conservación es el único motivo por el que se } \\
\text { puede reproducir una obra y no la ampliación del } \\
\text { catálogo por las necesidades de los usuarios o con } \\
\text { fines de fomento a la lectura. Adicionalmente, } \\
\text { en estas bibliotecas no pueden tomarse copias a } \\
\text { menos que puedan pagar a la entidad de gestión } \\
\text { de derechos. Vistas de esta forma, las Ecx.Li blindan } \\
\text { los espacios donde se usa la obra permitiendo al } \\
\text { propietario explotar sus derechos en cada uno de } \\
\text { ellos. }\end{array}$ \\
\hline
\end{tabular}

Fuente: elaboración propia con base en Ficsor (2008).

Finalmente, la tercera es la expropiación de derechos patrimoniales de autor. De todos, el único mecanismo legal sobre el que estos autores no dicen mucho y que es la expresión más clara de función social.

En DA, antes de que el plazo de protección se acabe, es posible expropiar los derechos cuando la obra se considere de gran valor e interés social, pero únicamente si los ejemplares están agotados, después de tres años de la última pu- blicación y sin probabilidades de que el titular publique una nueva edición (Ley 23 de 1982, artículo 20). Estos requisitos injustificados para expropiar solo tienen un referente en Colombia, que no tuvo mayor trascendencia. Se trata de la sentencia C-764/13. En ella, la Corte Constitucional decidió declarar inexequibles algunos artículos del proyecto de ley "por medio de la cual se rinde homenaje a la vida y obra del maestro de música vallenata Leandro Díaz". La argumentación, ambigua e incoherente, demuestra 
que el DA es un asunto del que el juez constitucional ${ }^{20}$ conoce muy poco. El Ministerio de Cultura expropiaría la obra del autor mencionado, pagando una indemnización a los titulares de derechos.

Según las objeciones presentadas por la Presidencia de la República, el Ministerio no explicó los motivos que conducían a la expropiación, sin observar que se encontraban en la Ley 23 de 1982. Por otra parte, según la Corte, la Presidencia y la Procuraduría, que la obra tenga un valor cultural es irrelevante. Además, si se le declara como patrimonio cultural de la nación, no es por ello expropiable ni es un motivo para limitar el derecho de los titulares. Tampoco hay motivos apremiantes e insalvables que lo justifiquen, fenómenos que restrinjan el acceso a la obra ni "la existencia de un conflicto general entre el disfrute del bien por parte de un particular y el aprovechamiento de la comunidad."

Todos esos argumentos se plantearon para rechazar la expropiación de la obra de Leandro Díaz. Adicional a ello, el sujeto, el objeto y la causa expropiandi ${ }^{21}$ no se hicieron explícitos, tam-

20 En esta sentencia se decide aceptar algunos artículos del proyecto de ley para el homenaje a Leandro Díaz, permitiendo la estatua que se hará del autor y la recopilación de sus obras que luego serán distribuidas por el Ministerio de Cultura. Lo que de todas formas implica que el Ministerio pague por los derechos de reproducción, distribución y comunicación al público a quien sea el titular.

21 Sentencia C-227/11: "La expropiación por vía administrativa no es otra cosa que la potestad que tiene la Administración de "privar" del derecho a la propiedad a los particulares, dirigida a desarrollar proyectos encaminados a la utilidad pública y al interés social, de acuerdo con un procedimiento específico y previo pago de una indemnización, en la medida que la persona natural o jurídica privada sacrifica sus derechos patrimoniales para satisfacer fines estatales. La expropiación comprende tres elementos característicos: ... La causa expropiandi o justificación presentada por el Estado para utilizar la figura de la expropiación. Ésta debe tener un objetivo que cumplir, que sea acorde con los fines de la utilidad pública e interés social." poco se observan los principios de legalidad, el debido proceso y el derecho a acceder a una indemnización justa, que no puede fijar un perito como sugería la ley. Se citan las sentencias C-370/9922 y C-227/11, para inferir requisitos adicionales a la expropiación en el DA según la Corte.

Siguiendo los parámetros jurisprudenciales citados, la Corte evidencia que la expropiación establecida [el proyecto de ley] no está soportada en la existencia de una incompatibilidad entre el título privado y el provecho general, [y], en la actualidad la obra del maestro no se encuentra en peligro y su acceso al público no está limitado. (CConst., C-764 de 2013, J. C. Henao).

A continuación, en la gráfica 1 presento un esquema con dos de los problemas $(\mathrm{P})$ que sugiere esta interpretación constitucional.

"El legislador debe establecer de modo expreso la causa expropiandi, contraída en primer término al señalamiento expreso y preciso de los motivos de utilidad pública o de interés social que pueden encontrarse en conflicto con el interés privado. Además, el legislador debe indicar los casos, en los que dicha expropiación se puede adelantar por vía administrativa, para que ella no sea un instrumento indiscriminado y abierto sino que constituya un procedimiento previsto en cada tipo de casos para satisfacer las necesidades de la utilidad pública y del interés social contenidas en la ley." 
Gráfica 1. Problemas de la interpretación constitucional acerca de la expropiación de derechos de autor con base en la sentencia C-764/13

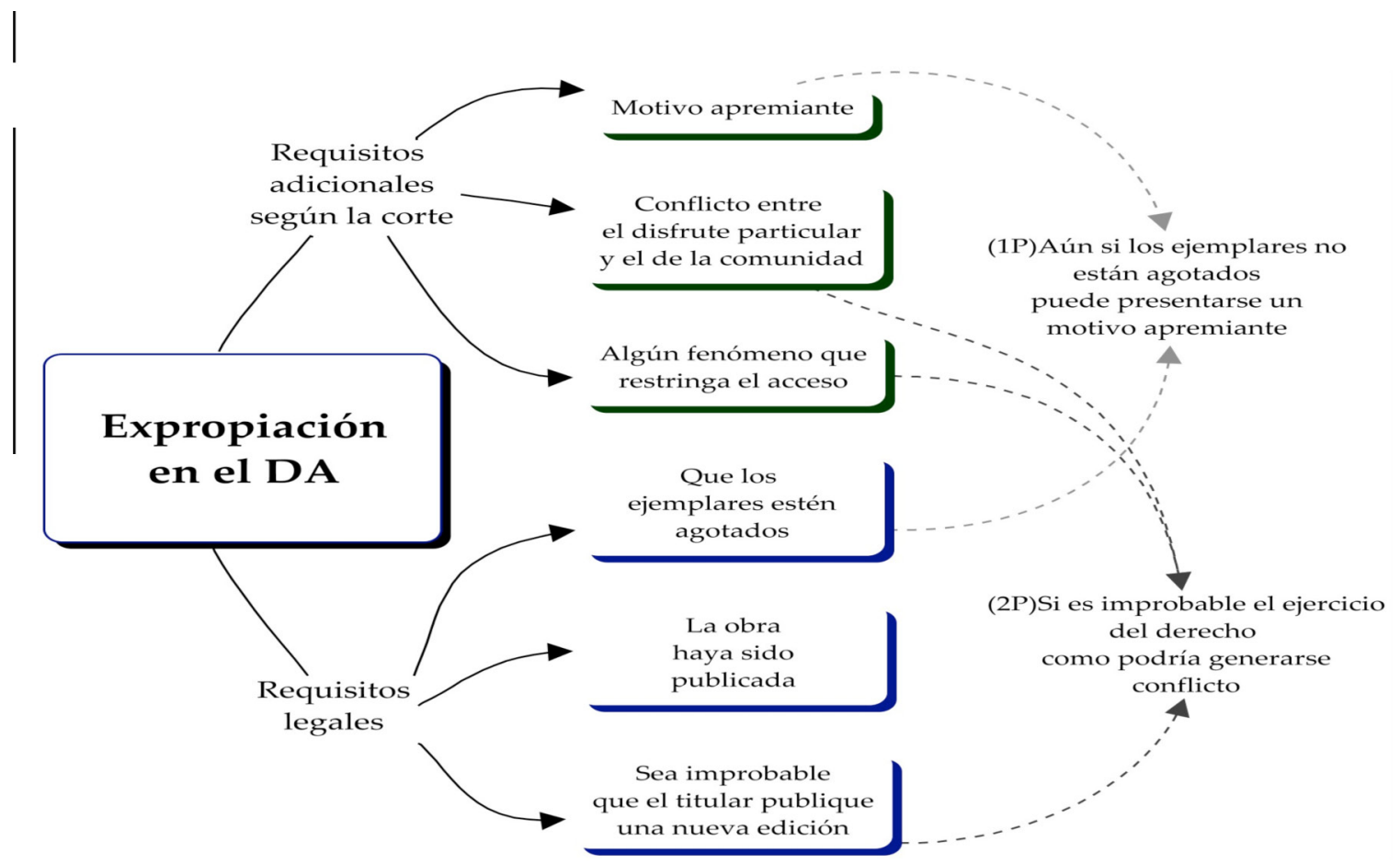

Esta forma de función social no ha visto su aplicación, esto es, no se han expropiado derechos sobre obras que quizá tendrían algún valor para la sociedad local. Como se mostró, no existe regulación clara ni avances en cuanto a la investigación sociojurídica en el derecho local sobre la necesidad de expropiar. Es en este sentido que el DA se vuelve insubstancial y estático. Aunque se requiere para proteger derechos potencialmente explotables, no hay evidencia concreta de la promoción al acceso al conocimiento y la cultura, que es parte de su finalidad y función social.

Ahora, uno de los autores que tiene en cuenta más variables de análisis que las netamente normativas es Juan Carlos Monroy (2009). En un estudio para la oMPI sobre las limitaciones o excepciones al derecho de autor y los derechos conexos en beneficio de las actividades educativas y de investigación en América Latina y el Caribe, propone la readaptación del derecho de autor conforme a las exigencias del entorno digital, sin dejar de ver la importancia de la educación que se ha venido desarrollando alí (ej. blending learning, cursos a distancia, material académico de back-up) y sobre todo la condición colombiana -y latinoamericana- de ser un país en vías de desarrollo, con bajos niveles de educación y una brecha social que impide el ejercicio de derechos y goce de libertades.

La propuesta de Monroy (2009, pág. 241 y ss.) puede resumirse de la siguiente forma: los derechos de autor son relativos, pues procuran un equilibrio entre el autor y la sociedad. El Esta- 
do debe encontrar el balance y concretarlos en leyes que definan: la duración de los derechos patrimoniales, las obras que pertenecen al dominio público, las causas de expropiación y un régimen de Exc.Li acorde con las realidades de cada país y las nuevas coyunturas tecnológicas. Aunque también insiste en que las tres formas clásicas de función social ${ }^{23}$ son las que responden a la búsqueda del equilibrio autor/sociedad, pero añade que los modelos alternativos de licenciamiento virtuales y sin ánimo de lucro contribuyen también a esto.

Los puntos en que su propuesta se torna igual a las lecturas reduccionistas, pero con un marco progresista-moderado, son visibles cuando acepta que el derecho de autor tiene ahora un marco de posibilidades y podría adaptarse para apoyar la educación y la cultura. Sin embargo, responde a varias de las objeciones al derecho de autor de una forma en que su progresismo se vuelve tenue, a saber:

Niega que haya una apropiación del conocimiento en el DA, (como sugieren algunos críticos), ya que protege la expresión original y no las ideas. Además, indica que "podría caerse en el facilismo de pensar que el acceso a toda creación debería ser libre y gratuita (...) si es con fines educativos" (Monroy, 2009, pág. 241). Esto lo

23 "El derecho de autor no es ajeno a la función social de la propiedad, y por eso está llamado a evolucionar al ritmo de las transformaciones sociales, culturales y económicas para garantizar la efectiva protección de los derechos de autores y titulares de derechos conexos en un marco de respeto y armonía con las necesidades de la sociedad en su conjunto, una de las cuales actualmente es el adecuado disfrute de las oportunidades y posibilidades que la tecnología digital y las redes digitales representan en beneficio de la cultura, la información, la educación y el acceso al conocimiento." (Monroy, 2009, pág. 242). soporta en un autor reaccionario, ${ }^{24}$ que insinúa cómo la exigencia de gratuidad de bienes protegidos por el DA podría devenir en no remunerar al autor.

Niega que el derecho de autor sea obsoleto, como lo reclaman muchos críticos. Esto lo hace caer además en un error de coherencia del texto, pues aunque finaliza sugiriendo modelos de adaptación a lo digital, al rechazar que el DA es estático el argumento parece poco coherente porque la idea de cambio o adaptación entraña al menos una consideración en cuanto a lo que existe: que es obsoleto, por ello requiere cambio. También rechaza el evidente carácter pro gremio del derecho de autor y el favorecimiento que reciben los titulares de derechos patrimoniales que no son (la mayoría de veces) los autores. A esta objeción responde que las industrias culturales son imprescindibles para la difusión y consumo de obras, aun cuando admite que el extremo más débil en una relación contractual es el autor.

Rechaza que la piratería favorezca la difusión del conocimiento en los países en desarrollo, y así cae en un error por ausencia de evidencia

24 Se trata de Victoriano Colodrón quien, según Monroy (2009, pág. 241), "plantea con acierto cómo no se escuchan similares argumentos para hacer gratuitos otros insumos y costos que los estudiantes y las instituciones educativas deben actualmente asumir, pudiendo disponer entonces de manera gratuita de otros bienes y servicios que se utilizan en la educación y el acceso al conocimiento: remuneración a los docentes por su trabajo hasta el pago de los gastos de agua, electricidad, mobiliario, conexiones a Internet, etc. ¿Por qué no deberían ser estos servicios gratuitos para los centros educativos y de investigación?, ¿el tener que pagarlos no constituye también un obstáculo para el desarrollo educativo? Si bien preguntas como las anteriores parecieran un poco absurdas, pregunta Colodrón, ¿por qué no suena entonces igual de absurdo pretender que ha de poder disponerse de manera libre y gratuita de las obras de los autores y editores, sin que su trabajo reciba la remuneración que merece?" 
empírica. Que la piratería sea un delito no niega que un ciudadano que adquiere una obra reproducida sin autorización, (obra pirata), no esté accediendo al conocimiento.

Afirma que "en el medio digital quienes más cometen piratería son personas con recursos suficientes para pagarse una conexión a Internet, un Pc, un iPod o un teléfono móvil, por lo menos" (Monroy, 2009, pág. 242). Sin embargo, no aclara cuántos son recursos suficientes, ni el estudio cuantitativo de los que más cometen piratería.

Pero, hay particularmente dos puntos que convierten la propuesta de Monroy en una lectura menos plana, pero reduccionista de corte liberal clásico. Primero, su idea de regular Internet pues "la libertad que es característica de Internet, no debe confundirse con la anarquía" (2009, pág. 242), y segundo, que el derecho de autor debe mantenerse neutral ante el precio de las obras y la duración de la explotación, sin que sea recomendable para los países en vías de desarrollo adoptar medidas de política pública que establezcan una protección mínima. Frente a esto último, el autor no tiene en cuenta que los costos de los niveles de protección los asume la sociedad, así como los plazos injustificables y excesivos (Bullard, 2008, pág. 26). Por ende, el consumidor potencial de una obra en un país en vías de desarrollo es solo el que puede asumir el precio que el titular decide fijar.

A pesar de todo, junto con Sofía Rodríguez (2004) este autor es uno de los que ha leído los límites al derecho de autor como función social en pro de la sociedad, poniendo en consideración algunas observaciones progresistas-moderadas. Se nota en ambos autores el esfuerzo por mantener un lenguaje neutral que, no obstante, les hace perder solidez para propuestas o agendas de investigación modernizadora.

Lo cierto es que estas lecturas siempre terminan defendiendo la institución con un alto nivel de fidelidad y alienación a las razones internas del derecho de autor. Es decir, mientras la ciudadanía virtualmente activa promueve críticas, -insisto en que pueden ser dispersas pero legítimas- que sitian las bases justificatorias del DA y por ende posibilitan su dinamismo social, las lecturas reduccionistas lo niegan todo, cuestionan las virtudes de lo digital y así rechazan la necesidad de repensar el derecho de autor para/en el contexto moderno y local.

El paroxismo de la discusión pública sobre DA tiene cada vez más voces, pero aún no se presentan respuestas a las críticas sino defensas automáticas, obviando que la justificación que se ha construido para la propiedad intelectual no desmiente el antagonismo entre propietarios y no propietarios (Waldron, 2012). Menos el hecho de que para proteger las creaciones se utilicen las mismas bases del régimen de propiedad privada, lo que aunque no es conveniente y genera escasez (Bullard, 2008) es inevitable. ${ }^{25}$ Pero esto ha sido obviado.

\footnotetext{
25 "Los costos de exclusión de la propiedad intelectual suelen ser muy altos. Ello es consecuencia de su carácter incorporal. Si quiero defender mi casa, basta construir una cerca (...) pero con la propiedad intelectual no es tan sencillo, basta recordar un poema para citarlo o una canción para cantarla (...) es un tipo de derecho que puede ser reproducido al infinito (...) por tanto el control sobre el mismo es realmente difícil." (Bullard, 2008, pág. 4).
} 


\section{B. Lecturas marginales}

Según Jeremy Waldron (2012), en la propiedad existen problemas de carácter justificativo tendientes a responder el porqué de la institución, así como las razones y bases por las cuales traerá beneficios su protección. La justificación que se ha construido en el sistema continental para el DA es deontológica y no consecuencialista; es decir, se fija en las ventajas de protección para el sujeto y no en los beneficios para la sociedad (Waissman, 2012; Spector, 1988). Pero, la comunidad académica anglosajona, ${ }^{26}$ representada por Lawrence Lessig, James Boyle y Neil Weinstock Netanel, ha comprendido la necesidad de revisitar las hipótesis de trabajo sobre las que el copyright es operativo en el contexto digital, logrando un nivel más alto de consecuencialismo mientras toma (mucha) distancia de la comunidad académica continental sobre DA que todavía no llega al nivel propositivo ni supera el descriptivo.

En EE. UU. en vez de función social está la social obligation norm (Alexander, 2013) que comprende la propiedad como un derecho con inherentes obligaciones sociales y de esta forma es que Lessig, Boyle y Weinstock la concretan en sus propuestas y proyectos académicos. ${ }^{27} \mathrm{La}$

26 Al respecto, uno de los trabajos menos contemporáneos pero más interesantes sobre el derecho de autor es el de Waldron, J. (1992). From Authors to Copiers: Individual Rights and Social Values in Intellectual Property. Chicago-Kent Law Review, 68, 841-887. Obtenido de: http://scholarship.kentlaw.iit.edu/cgi/viewcontent.cgi?article=2894\&context=cklawreview

27 Ninguno de ellos habla literalmente de función social pero todos tienen una posición frente a la necesidad de imponer mayores obligaciones al titular y convertir el copyright en un elemento pro sociedad, cultura y educación. Estas son a su vez las finalidades de la función social del DA, luego es posible incluirlas como lecturas o versiones de esta. obligación es diferente en cada autor: compartir el conocimiento que los autores crean mediante sistemas de licencias (Lessig), reducir el tiempo para que una obra ingrese en el dominio público (Boyle) y organizar los saberes que crean las obras de forma que el copyright sirva para la construcción de las sociedades civiles democráticas (Netanel).

En otro sentido los otros lectores marginales, los hacktivistas, no tienen una agenda clara, pero son individuos que desobedecen (privadamente, como cuando se es consumidor ilegal por la descarga de una canción o colectivamente) reivindicando un derecho al acceso, de manera que el protoanarquismo abstracto ${ }^{28}$ característico de los desobedientes antiguos, ya no fundamenta la acción, ${ }^{29}$ sino la institucionalización, el respeto por las normas y el deseo de que las conductas modernas de consumo virtual sean respetadas y reconocidas como formas de concretar el derecho a la cultura y el acceso al conocimiento.

Esta reivindicación requiere ser clarificada. La mayoría de hacktivistas son consumidores de información que exigen a las instituciones que protegen el DA su derecho al ocio. Este es un fenómeno relacionado con la mayor disponibilidad de tiempo libre y la democratización de la vida cultural en espacios donde el sujeto decide

\footnotetext{
28 Usando la expresión de Stuart Hall.

29 Pero esto no es así en todos los casos. Movimientos radicales como Anonymus generan un efecto adverso porque vulneran derechos a la privacidad y libertad informática, con amenazas a diversos sectores sin ninguna finalidad aparente, lo que generará por parte de las instituciones la necesidad de regular la Internet para evitar estos delitos que no guardan relación con la reivindicación de derechos.
} 
cómo organizar lo que quiere consumir y de qué forma lo hará. ${ }^{30}$ En esta encontramos, como ya se dijo, a RedPaTodos, Copyleft, la Fundación Karisma y la ong Derechos Digitales. Varios de estos movimientos usan la propuesta de Lessig y extienden sus proyectos como organización intentando instituir una crítica al derecho de autor. Estas lecturas, no obstante el dinamismo que permiten para la discusión pública, tienen varios problemas en sus propuestas que mencionaré al paso que me voy ocupando de ellas.

Algunos autores están de acuerdo en que otros consuman sus obras sin tantas restricciones, que la duración del derecho sea la mínima, que la obra pueda ser reeditada y, en algún caso, que se pueda usar sin ninguna restricción. Proponen en cambio la libre disposición de los derechos de autor, lo cual es posible tanto en el régimen de derecho de autor continental como en el anglosajón (Perilla, 2013).

La libre disposición de derechos del propietario es el eje de la propuesta de (Lessig, 2001, 2004). Su propósito es generar difusión pública de forma gratuita (en línea) para todos mediante las licencias Creative Commons (cc), que consisten en aumentar la capacidad del autor de una obra a partir de licencias con las cuales decide su circulación y futura utilización. La mayoría de revistas indexadas, ${ }^{31}$ donde están depositados

30 Según la Carta del Ocio de la World Leisure and Recreation Association, "all people have a basic human right to leisure activities that are in harmony with the norms and social values of their compatriots. All governments are obliged to recognise and protect this right of its citizens."

31 Menciono tres bastante significativas: Directory of Open Access Journals (http://doaj.org/); voc papers, revista sobre la sociedad del artículos de académicos en el mundo, utilizan el sistema cc. Las licencias son un contrato entre el autor y el usuario de la obra, donde el primero indica cómo y en qué contexto debe utilizarse. Siguiendo a Xalabarder (2006, pág. 7), se clasifican así:

1) Reconocimiento: en cualquier explotación de la obra autorizada por la licencia hará falta reconocer la autoría.

2) No comercial: la explotación de la obra queda limitada a usos no comerciales.

3) Sin obras derivadas: la autorización para explotar la obra no incluye la transformación para crear una obra derivada.

4) Compartir igual: la explotación autorizada incluye la creación de obras derivadas, siempre que mantengan la misma licencia al ser divulgadas.

Surge porque Lessig (2004) se opone a la expansión injustificada de derechos del sistema tradicional y persigue compartir el conocimiento de forma alterna a como lo hace el sistema de copyright. Según puedo observar, la iniciativa (cc), bastante progresista, se asienta en dos valores también liberales: la individualidad y la comunidad. Estos últimos, no obstante lo novedoso, valioso e impactante de la propuesta, no se realizan porque Lessig sobrevalora las virtudes de la Internet y las posibilidades de cambio que se supone lleva consigo. Acierta en su crítica: el

conocimiento, de la Universidad Oberta de Catalunya; y Scientific Electronic Library Online-SciELO, entre muchas otras. 
DA/copyright se convierte en un tema interesante, en la medida que se lo discute desde distintos sectores (social, político, jurídico, artístico) y también a partir de la interacción que tiene el texto legal con las realidades a las que se enfrenta. Así, los problemas que tuvieron los editores antes del Convenio de Berna son similares a los de los productores y titulares de derechos actualmente con la reemergencia de Internet. Lessig (2004), no sin razón, observa las irregularidades que el sistema anglosajón creó mediante el incremento del tiempo de protección de obras y la criminalización de los nuevos actos privados (y públicos) de consumo, que agrandan la barrera para el acceso al conocimiento. Pero creo que la oportunidad de discutir más allá de la coyuntura digital no fue aprovechada por este autor y ese es su desacierto.

Se fija con excesiva fe en la virtud de las nuevas tecnologías de la información y lo que permiten para la cultura y la educación. No obstante, no hay ningún filtro en la Internet, ni mediadores del contenido como los que sí existen en el mundo análogo, como anota Roger Chartier (2012). Estos se encargaban de la jerarquía de los discursos, indicaban al consumidor que, por ej., los libros eran obras más cultas que los folletos, pero estos no existen en Internet y los que quizá podrían hacer sus veces (universidades/ bases de datos de revistas/repositorios) en el mundo digital, no son las opciones de consumo más usadas. Adicionalmente, el problema de adjudicar estos beneficios a este medio es que bajo esta creencia algunas instituciones públicas, una vez garantizan el acceso, consideran que consecuentemente lograron inclusión so- cial y potenciaron la capacidad de aprender. En Colombia, según el Informe de gestión al Congreso, del Ministerio de Tecnologías de la Información y las Comunicaciones (2011), existe una cobertura cada vez más amplia de la red en el país, la brecha digital ya no es obstáculo y existen más internautas de todas las edades que usan la Internet como única posibilidad de acceso a contenidos a los que antes hubiese sido impensable acceder. Esto es sin duda una gran ventaja; sin embargo, la promesa de la cooperación virtual sin restricciones no significa per se una sociedad más culta o educada y en muchos casos solo es una red de consumidores.

Pero muchos movimientos usan a Lessig (2001, 2004), sin parafrasearlo, con la promesa de que el cambio social puede lograrse mediante la cooperación virtual. Pese a ello, los logros en materia de educación para países en vías de desarrollo no son más luego de la ampliación de redes $^{32}$ y el uso de las cc. Creo, entonces, que no hay que forzar el contenido argumentativo de la crítica de Lessig y de los usos de las licencias cc. Estas son función social -únicamente- en la medida que promueven la participación de la sociedad en el acceso a las obras que crean los autores y que estos de forma directa y voluntaria deciden poner a su disposición.

Por otra parte, James Boyle (2010) -también promotor de las cc-, agrega algunos puntos interesantes en relación con el dominio público

32 Al respecto ver el informe: La generación interactiva en lberoamérica 2010. Niños y adolescentes ante las pantallas. Disponible en: http://www.generacionesinteractivas.org/upload/libros/La\%20 Generacion\%20Interactiva\%20en\%20lberoamerica\%202010.pdf 
y la creatividad. En primer lugar, indica que los derechos de propiedad sobre intangibles deben ser la excepción y no la regla, pues entre menos cercamientos haya del uso de las ideas, mayores posibilidades creativas habrá. Sus argumentos en relación con el dominio público contribuyeron a la creación de un Manifiesto ${ }^{33}$ firmado por varios académicos.

Esta lectura de Boyle es la versión que sugiere adaptación o deceso de la institución. Ante Internet el DA/copyright es arcaico, por ese motivo el legislador ha pretendido prohibir y castigar los actos de consumo que se multiplican por parte de los usuarios. El efecto de esa nueva regulación genera más incomodidad con esta institución. Las posibilidades conducen solo a la adaptación, que podría describir, de acuerdo con algunas recomendaciones del Manifiesto del Dominio Público, de la siguiente forma:

1. Reducir el plazo de protección para todas las obras.

2. Las obras deben entrar al dominio público mundial o "estructural".

3. Castigar a quienes se apropien de obras en el dominio público.

4. Facilitar el acceso a obras huérfanas: "Estas obras deben estar disponibles para su reutilización productiva por la sociedad en su con-

33 Este Manifiesto del Dominio Público fue firmado por Lessig y Boyle, su traducción estuvo a cargo de otro académico virtualmente activo, Ignasi Labastida. Disponible en: http://www.publicdomainmanifesto. org/spanish, así como en el Center for the Study of the Public Domain: https://web.law.duke.edu/cspd/spanish/manifesto junto" (http://www.publicdomainmanifesto. org/spanish).

5. Etiquetar, preservar y ofrecer libremente las obras que estén en el dominio público institucionalmente.

6. Que puedan ofrecerse las obras de dominio público sin ninguna prohibición tácita o expresa del ordenamiento legal.

7. Tener en cuenta la posición del autor al establecer nuevos límites y excepciones a los derechos de autor.

Estas propuestas surgen como consecuencia del trabajo de Lessig, Boyle y los académicos anglosajones que procuran una crítica a la institución pero manteniendo sus bases. Son una caja de herramientas que aún no adquieren suficiente voz en el campo de los expertos locales, aunque sí se han creado muchos movimientos sociales virtuales cuyas bases son estos autores, que tienen agendas de todo tipo.

La Fundación Karisma sigue los parámetros de Lessig y Boyle, pues la comunidad virtual distiende las fronteras y sugiere que el mismo problema de acceso que observaron estos autores también existe en los otros contextos geográficos por encima de la tradición continental o del Common Law. Carolina Botero ${ }^{34}$ es

34 En el desarrollo de esta investigación no encontré textos académicos de esta autora como los de Lessig y Boyle, pero sí columnas de opinión y asistí a dos eventos en los que esta promotora participó como ponente. Por ese motivo presento sus argumentos a partir de allí. Existe un autor quien también debate acerca de la libertad y gratuidad en el software: Stallman, R. (1997). Why Software Should be Free. In A. Moore (Ed.), Intellectual Property: Moral, Legal, and International Dilemmas. Lanham, MD: Rowman and Littlefield. 
una ciudadana virtualmente comprometida con esta causa. Su posición puede resumirse de la siguiente forma: Internet es un derecho fundamental y como tal no debe ser restringido. En este sistema se encuentra la mayor cantidad de información disponible que debe compartirse de forma comunitaria y expedita. El argumento de la función social que puede observarse en esta iniciativa es similar a la de Lessig y Boyle: comunidad en vez de individualidad, compartir los bienes y oponerse a su "utilización egoísta" (Benítez, 2013).

Igual que los anteriores, sobrevalora Internet y se une al movimiento mundial por el acceso a la red, que lleva ya suficiente tiempo como para replicar insistentemente el mismo discurso. Así como la dogmática descriptiva y ordenadora analiza el DA local, estos movimientos reiteran la condición suprema de Internet, ${ }^{35}$ que en realidad es un espacio usado para el ocio, que por supuesto es un derecho, pero que no conduce necesariamente a la creación de conocimiento o a la promoción de la educación (Spink, Partridge y Bernard, 2006).

Otra crítica posible es que su desobedecimiento y actitud contestataria, aunque está nomo orientada (López et al., 2013) no es legítima dentro marcos más amplios de exigencia de derechos. Es decir, su conducta de oponerse a las barreras para el acceso a la información la orientan otros derechos considerados como superiores a los primeros: así, el derecho a la educación-cul- tura en Internet es superior a la explotación comercial del DA. Pero existen condiciones reales (no virtuales) de desigualdad y falta de acceso a la educación, como para abrogarse esa causa con un canal de información sin filtros.

En ese sentido, acierta Ortega (2011) cuando señala que las posiciones de los grupos hacktivistas es la de los consumidores modernos. La gratuidad es lo que persiguen los grupos que están en contra del derecho de autor ${ }^{36}$ en general y de cualquier regulación jurídica de la Internet, particularmente. Aun cuando esto es legítimo, parece irrisorio considerar que los mayores niveles de acceso impactan la educación y que el derecho al ocio y la gratuidad sobre bienes que se pueden consumir son cultura. Entonces, considero que debería reemplazarse la exigencia de acceso orientada por la educación y la cultura por la del derecho al ocio. Esto daría mayor legitimidad a los movimientos ciberlibertarios para no caer en una paradoja similar a la del antimaterialismo de la que hablan (Heath y Potter, 2004), pues a veces su resistencia y oposición a las industrias culturales o el DA son una venta de otro producto precisamente: el del movimiento por la cultura libre.

No sé qué tan estratégica es la oposición de los movimientos por la cultura libre, pero han logrado mover a los lectores reduccionistas, avocados a revisar no solo si Internet rompe los marcos en los que el DA "solía funcionar", sino incluso si en el mundo análogo ha tenido bene-

\footnotetext{
36 Los textos, ponencias y eventos que se realizan siempre se plantean en términos de ataque y defensa. Así en Lessig (2004).
} 
ficios sociales, y quizá eso sea una buena parte de la crisis.

Por otro lado, he insistido a lo largo de esta parte en la duda sobre las virtudes de la Internet, si se tiene en cuenta que el acceso a la información de cualquier tipo no podría pensarse -al menos no con tanto optimismo- como el ideal de cultura y democracia postacceso.

La función social del derecho de autor sobre la base de la solidaridad tiene un último uso y es la fijación de objetivos para la construcción de una democracia civil, pero no para el acceso a cualquier contenido sino al más cualificado. En este sentido, presento la última propuesta -quizá de estas lecturas la más interesante- y es la de Netanel. ${ }^{37}$ Este autor sugiere que apoyar la difusión de información y opinión con medios de comunicación protegidos por el copyright contribuye a la formación de un orden democrático más abierto al debate público. Pero la protección no significa que todos los países adopten el mismo sistema de protección al estilo occidental. Hay que tener en cuenta para el diseño

37 Quien además junto con "Raymond Ku (2001), Glynn Lunney (2001) y William Fisher III (2004) han propuesto un mecanismo de compensación para los artistas y propietarios del copyright en los cuales el gobierno debería imponer tasas en bienes y servicios asociados a las redes p2p. Aunque algunos hablan de tasas y otros de impuestos, tarifas o aranceles, en definitiva todas las propuestas derivan del modelo de licenciamiento compulsivo que se usó repetidas veces en el pasado para poner fin a disputas por derechos de autor en nuevos medios y tecnologías. En Estados Unidos este fue el modelo que se siguió, por ejemplo, a fines de los años 60 cuando surgió la televisión por cable como un servicio pago. Según Yu (2005), este modelo también es popular en Canadá, Alemania y otros países europeos, que han aplicado impuestos sobre medios de grabación en blanco y equipos para compensar a los artistas y compositores. Incluso algunos de estos países han impuesto aranceles sobre reproductores portátiles de MP3 y bienes y servicios ligados a las redes $p 2 p$ como grabadoras de CDs." (Zukerfeld y Perrone, 2007, pág. 213). de estas leyes, las cuestiones particulares de las sociedades, los sectores de la industria y las condiciones locales ${ }^{38}$ como base o fundamento de la construcción o desarrollo democrático ( $\mathrm{Ne}$ tanel, 1998).

Adicionalmente, siguiendo a Zukerfeld (2010), la de Netanel (1998) es una teoría minimalista que también busca que se reduzca a mínimos justos la duración de derechos, de forma que más personas puedan crear nuevas obras sobre obras derivadas; esta clase de acciones contribuye al debate público y a la educación ciudadana. Concedido esto, debe igualmente estimularse a quienes producen las obras que luego serán parte del acervo con el que es posible construir democracias o culturas civiles.

El derecho sobre obras debe existir, garantizando los estímulos que los productores de conocimiento requieren y que visibilizan la formación de estas democracias que Netanel (1998, pág. 266) define así:

Una cultura democrática se basa en un compromiso generalizado de la democracia entre las élites políticas y las masas. Una voluntad de compromiso de los opositores políticos; y un

38 "As domestic cultural industries become more established and as ideological motivation wanes, copyright's role in promoting the dissemination of information, opinion, and entertainment in newly democratic states may become more significant. However, copyright generally will not be able to contribute significantly to that dissemination unless and until the nascent democracy's economy is sufficiently developed to support commercial publishing and distribution... Developing countries that accord copyright protection for foreign Works often face shortages of those works, either because Western publishers have little interest in licensing or distributing their works in developing countries, or because developing country publishers and consumers are unable to bear the additional costs of paying the copyright royalties that Western publishers demand." (Netanel,1998, pág. 265). 
cierto grado de civilidad y la moderación en el discurso político.

De esa forma, se generan sectores creativos, genuinamente independientes de industrias o del Estado (Zukerfeld, 2010), y los países en vías de desarrollo avanzan en la construcción de una cultura democrática. ${ }^{39}$

\section{Lecturas huérfanas}

Estos autores presentan literalmente la idea de la función social del derecho de autor. En las lecturas marginales previas no hay una alusión explícita; sin embargo, todas coinciden en que la creatividad tiene como fundamento la solidaridad que conduce a compartir los resultados de esta y no la individualidad, de manera que sus exigencias en los puntos específicos que presenté son una forma concreta de la función social. Pero Paul L. C. Torremans (2004) y Christhophe Geiger (2013) señalan que la crisis de legitimidad del derecho de autor que se muestra incapaz de garantizar el balance de interés entre sociedad y titular podría ser solucionada por la constitucionalización ${ }^{40}$ de este derecho.

39 "A democratic culture, supported by the widespread dissemination of information and opinion, an independent and pluralist media, and a belief in the efficacy of individual contributions to public discourse, is central to that process of democratization. In some circumstances, particularly in advanced democracies, copyright can contribute significantly to those constitutive factors. In others, copyright-at least a proprietary set of rights modeled on Western copyright-would have a marginal or negative impact on their realization. To assert the principle that copyright should further democracy is thus not to require that all countries adopt Western-style copyright laws. It is rather to examine particular issues, market sectors, and local conditions with an eye towards tailoring copyright towards furthering democratic development." (Netanel, 1998, pág. 349).

40 Hablan fundamentalmente de crisis de la propiedad intelectual en general.
Dos juristas alemanes, señala Geiger (2013, págs.104-106), Josef Kohler y Otto von Gierke dieron a conocer en el siglo xIx la constitucionalización del derecho privado, que busca la reconciliación de intereses entre individuos propietarios y la sociedad. Acorde con esto, el artículo 27 de la Declaración Universal de Derechos Humanos de 1948, señala: “Toda persona tiene derecho a la protección de los intereses morales y materiales que le correspondan, por razón de las producciones científicas, literarias o artísticas de que sea autora."

Lo anterior implica que el derecho de autor es un derecho fundamental y su interpretación debe seguirse de acuerdo con esta declaración cuyo rango es de obligatorio cumplimiento. Torremans (2004) sugiere que también en ese artículo hay un elemento de rango constitucional: "Toda persona tiene derecho a tomar parte libremente en la vida cultural de la comunidad, a gozar de las artes y a participar en el progreso científico y en los beneficios que de él resulten." Aclara que esta libertad no debe interpretarse como gratuidad porque los derechos de los no propietarios se encuentran también garantizados.

Con base en los argumentos de estos autores mi lectura es que la función social en la propiedad privada debe actuar para la imposición de obligaciones ineludibles y en beneficio de la comunidad (Crawford, 2013; Alexander, 2013; Bonilla y Foster, 2013), pues la concepción individualista del autor es una abstracción sin realidad alguna (Duguit, 1926).

Conforme a la doctrina del precitado autor el hombre nace y vive en sociedad, no puede vivir 
sino en sociedad. En ella hay unas necesidades comunes (solidaridad por similitud), y unas necesidades y aptitudes diferentes (solidaridad por división de trabajo). La sociedad es más fuerte cuando los lazos entre sus integrantes son más estrechos, luego la regla de derecho debe inspirarse en el principio de la interdependencia social, que obliga a cada hombre a cumplir una misión social y a no perjudicar la solidaridad. Es decir, que el titular de una obra debe explotarla, debe "ponerla a producir" (Bonilla y Foster, 2013); eso implica reducir las barreras de acceso para la creación de obras derivadas y disminuir el tiempo de protección, de manera que no se mantenga durante un tiempo excesivo un derecho que solo tuvo un momento de trabajo específico para ser creado.

Ahora, continuando con Duguit (1926), la libertad es vista como un derecho solo si el hombre por medio de su actividad logra el mayor desarrollo posible; solo disfruta de ese derecho a la libertad en la medida en que consagre su propia actividad a la realización de la solidaridad social.

En ese sentido, la obligación para las industrias creativas pareciera tomar más forma si se tiene en cuenta que estas deben contribuir al equilibrio real en contextos desiguales donde el consumidor -por ejemplo, América Latina- no tiene la capacidad de pago que estas quisieran (Gargarella, 2011) y sin embargo tiene derecho a la educación, a la cultura y el ocio desde las obras que se crean.

Mi lectura es breve y parcial, se basa en las lecturas huérfanas: la función social tiene mucho po- tencial en el derecho de autor local pues podría aplicarse tanto para la expropiación de obras protegidas por el DA, generando efectos reales de eficacia normativa, como para la creación de nuevos límites congruentes con la realidad local y -debido a que es una razón interna propia del derecho-con las exigencias de estandarización y reforma legal del discurso de los derechos de propiedad intelectual. Un derecho de autor con una función social, además de mayor legitimidad permite el desarrollo de las capacidades de los no propietarios que dependen en gran medida de la circulación de las obras disponibles para su aprendizaje y autoconstrucción. ${ }^{41}$

\section{CONCLUSIONES}

Así como los debates por la propiedad sobre la tierra han generado un sin número de posiciones frente a lo que es propiedad y los lugares donde deberían ubicarse sus límites, en materia de obras intangibles, que son un insumo para el conocimiento, las cosas no han sido distintas. Estas lecturas que presenté permiten entrever los múltiples usos -implícitos y explícitos-que ha tenido esta idea fuerza en el derecho de autor; así que el debate entre la versión clásica liberal del propietario, cuyo único límite para el ejercicio de derechos es el interés público, y una comunista moderada que reivindica un derecho de propiedad colectivo en una coyuntura carac-

\footnotetext{
41 "La idea de prosperidad humana (...) entiende que los sistemas de propiedad establecen reglas básicas que hacen posible la capacidad de la gente (...) es esencial que esas reglas se establezcan no solo para proteger los intereses particulares, sino también para proteger a las personas como miembros de comunidades y sociedades más grandes." (Crawford, 2013, pág. 102).
} 
terizada por la ausencia de barreras formales, mueve la forma en que es posible pensar acerca del derecho de autor y sugiere mucho acerca de cómo podemos investigar este objeto.

Las lecturas reduccionistas de la función social indican que esta es el dominio público, además de las limitaciones y excepciones. Dispositivos ambos que no están justificados, e incluso en cuanto a su operatividad no presentan claros beneficios a favor de los no propietarios. Así, por ejemplo, las bibliotecas públicas deben pagar por concepto de derechos reprográficos las copias del material que tomen, y no pueden ampliar su catálogo para brindar una oferta cultural más amplia porque solo pueden reproducir el material con fines de conservación.

Antes de la era digital, en lo que alguno de los autores llamó época armoniosa, no hubo ninguna expropiación a derechos patrimoniales de autor que permitiera ver cómo opera este derecho directamente en la participación de la vida cultural. Por el contrario, la expropiación contenida en una norma preconstitucional sugiere una serie de requisitos incoherentes que nunca darían lugar a la realización de esta. No obstante, las lecturas reduccionistas moderadas proponen tener en cuenta la condición de país en vías de desarrollo de Colombia, y el diseño de excepciones y limitaciones más amplias a los fines educativos.

Las lecturas marginales se instalan fundamentalmente en la convergencia digital. Aunque la Internet ha sido una buena excusa para discutir la eficacia del DA/copyright, pues allí es posible lograr la otra consecuencia que prometen las le- yes sobre derecho de autor: el acceso a la cultura y la educación no necesariamente abarca todo el marco de discusión posible sobre la materia. Más allá de esto, la solidaridad y contribución directa de los propietarios con el aporte de sus obras pone de presente dos valores en los que precisamente la función social se fundamenta. Algunos de los movimientos que se encuentran en estas lecturas deben modificar sus agendas, pues la reivindicación del derecho a la cultura y la educación no es algo que restringa el DA per se, por lo cual requieren fijarse más allá de lo virtual. Estas dos primeras lecturas se presentan en congresos y seminarios sobre la materia, usando conceptos como "la defensa del derecho de autor" o "la lucha contra el copyright en pro de la libertad"; pero parece que esto caricaturiza el escenario que podría ser más fructífero y con menos contenido valorativo.

Las lecturas huérfanas brindan un marco legal y teórico donde es posible entender el DA (Chapman, 2001) como un derecho fundamental que tiene dos elementos inherentes: 1) la protección moral y patrimonial de las obras y del autor, y 2) la promoción en la participación en el progreso científico o cultural. Desde estos elementos presenté una lectura posible de la función social que en términos pragmáticos podría entenderse: catálogos más grandes de obras que se puedan ofrecer a usuarios en bibliotecas, colegios y universidades; la reducción de prohibiciones en el ámbito educativo; y delegar a una institución pública - que exista- la gestión del dominio público $^{42}$ dando a conocer con amplia difusión las

42 Por ahora el proyecto de Ley 306 de 2013, que modifica la Ley 23 de 1982 no dice nada en relación con la custodia de obras que están 
obras en pro de la construcción cultural de los ciudadanos.

Con todo, lo que sugirió este texto es que la función social es una idea fuerza que permite repensar desde el campo jurídico local la eficacia y justificación del derecho de autor. Uno de sus valores agregados es que no atiende a las lógicas propias de los diseños legales transfronterizos de que hablé en la primera parte; por el contrario, es una herramienta para atender las necesidades locales más relevantes -que también son finalidades del DA- como la promoción de la cultura o el fortalecimiento de la educación, esto sin desestimar la posibilidad de un lucro justo para los titulares de derechos patrimoniales.

Aunado a lo anterior, la cita con que inicia este texto resalta la importancia de que los sistemas de propiedad, como el DA, establezcan reglas menos individuales brindando un marco para el desarrollo de capacidades de quienes no son titulares o propietarios de derechos, en tanto que de eso se trata la función social actualmente.

Ahora bien, en el DA aquello puede concretarse expropiando derechos patrimoniales; gestionando el dominio público; expropiando obras de notable reconocimiento que se requieran públicas y gratuitas; ampliando las excepciones y limitaciones; reduciendo los intermediarios para acceder a las obras; incentivando los sectores culturales con subsidios que puedan

en el dominio público, y esta obligación contenida en la actual Ley 23 quizá se desatienda dada la atención que se tiene con los "nuevos" consumos digitales. generar futuras reducciones en el precio; invirtiendo en el teatro, el cine local; ampliando la oferta de distribuidores; garantizando formatos adaptados de obras aptos para personas con capacidades distintas; estructurando sistemas de bibliotecas públicas con catálogos siempre actualizados; entregando ejemplares de obras de forma gratuita a instituciones educativas. Así será legítimo pedir mayor nivel de cumplimiento o respeto por el DA, pero sobre todo cumplir la promesa de que este promueve la existencia de un cultivo sostenible de expresiones originales de autores para personas que pueden usar las obras, cosechando otras, desarrollando sus capacidades, posibilitando así una red estable de conocimiento y no simplemente una de lucro inmediato y sin riesgo. Esa dimensión garantista es buena parte de la ruta que concreta el DA como función social y lo hace compatible con un modelo democrático acorde con las realidades de nuestras sociedades.

\section{Referencias}

1. Alexander, G. (2013). Aproximaciones teóricas contemporanéas a la función social de la propiedad. En D. Bonilla, La función social de la propiedad (págs. 29-70). Buenos Aires: Eudeba.

2. Alviar García. H. y Villegas del Castillo. C. (2012). La función social de la propiedad en las constituciones colombianas. Bogotá, CoIombia: Universidad de los Andes, Vicerrectoría de Investigaciones. 
3. Antequera Parilli, R. (2007). La observancia del derecho de autor y los derechos conexos en los países de América Latina. En F. Zapata López, S. Schuster, E. Piedras, R. Antequera Parilli y D. Lipszyc. Diagnóstico del derecho de autor en América Latina. Bogotá: Centro Regional para el Fomento del Libro en América Latina y el Caribe.

4. Batista, E. y Coral, J. (Enero 1, 2010). La función social de la propiedad: La recepción de León Duguit en Colombia. Criterio Jurídico, 10(1), 59-90.

5. Benítez Caorsi, J. J. (2013). Solidaridad contractual. Noción posmoderna del contrato. México: Editorial UBIJUS/Madrid: Editorial Reus, S. A.

6. Bercovitz, R.-C. R. (2009). Manual de propiedad intelectual. Valencia: Tirant Lo Blanch.

7. Bonilla, D. (2009). Teoría del derecho y trasplantes jurídicos. Bogotá: Siglo del Hombre.

8. Bonilla, D. (2013). El liberalismo y la propiedad en Colombia. Propiedad-derecho y propiedad-función. En D. Bonilla, La función social de la propiedad (págs. 153-214). Buenos Aires: Eudeba.

9. Bonilla, D. y Foster, S. (2013). La función social de la propiedad en perspectiva comparada. En D. Bonilla, La función social de la propiedad (págs. 11-26). Buenos Aires: Eudeba.
10. Boyle, J. (2010). The public domain: enclosing the commons of the mind. New Haven, Conn: Yale University Press.

11. Bullard, A. (2008). ¿Es la propiedad intelectual un robo? SELA. Seminario en Latinoamérica de Teoría Constitucional y Política. Documento disponible en: http://www.law. yale.edu/documents/pdf/sela/Bullard_Spanish.pdf

12. Cavalli, J. (2006). Génesis del Convenio de Berna para la protección de las obras literarias y artísticas del 9 de septiembre de 1886. Bogotá: Ministerio del Interior y de Justica, Dirección Nacional del Derecho de Autor, Telecom.

13. Chartier, R. (2012). Prólogo. Historia de la lectura en el mundo occidental. México: Taurus.

14. Chapman, A. R. (Julio-Septiembre de 2001). La propiedad intelectual como derecho humano: obligaciones dimanantes del apartado c) del párrafo 1 del artículo 15 del Pacto Internacional de Derechos Económicos, Sociales y Culturales. Boletín de derecho de autor, XXXV(3), 4-39.

15. Congreso de la República de Colombia. (28 de enero de 1982). Ley 23 de 1982. Sobre derechos de autor.

16. Convenio de Berna para la protección de obras literarias y artísticas. Septiembre 9 de 1886. 
17. Corte Constitucional de Colombia. Sentencia C-227 de 2011 (M. P.: Juan Carlos Henao Pérez; marzo 30 de 2011).

18. Corte Constitucional de Colombia. Sentencia C-370 de 1999 (M. P.: Carlos Gaviria Díaz; mayo 27 de 1999).

19. Corte Constitucional de Colombia. Sentencia C-764 de 3013 (M. P.: Jorge Iván Palacio Palacio; noviembre 6 de 2013).

20. Courtis, C. (2003). Enseñanza jurídica y dogmática en el campo jurídico latinoamericano: apuntes acerca de un debate necesario. En M. García y C. Rodríguez (Edits.), Derecho y sociedad en América Latina: un debate sobre los estudios jurídicos críticos (págs. 7591). Bogotá: Instituto Latinoamericano de Servicios Legales Alternativos/Universidad Nacional de Colombia, Facultad de Derecho, Ciencias Políticas y Sociales.

21. Courtis, C. (2006). Observar la ley: ensayos sobre metodología de la investigación jurídica. Madrid: Editorial Trotta.

22. Crawford, C. (2013). La función social de la propiedad y la capacidad humana de prosperar. En D. Bonilla, La función social de la propiedad (págs. 95-150). Buenos Aires: Eudeba .

23. Duguit, L. (1926). Manual de derecho constitucional. Madrid: Editorial Francisco Beltrán.

24. Dusollier, S. (Marzo 4 de 2011). Estudio exploratorio sobre el derecho de autor y los derechos conexos y el dominio público. Bélgica: Organizacion Mundial de la Propiedad Intelectual.

25. Ficsor, M. (2008). Limitaciones y excepciones al derecho de autor en el entorno digital (S. R. Moreno, Trad.). Bogotá: Centro Regional para el Fomento del Libro en América Latina, el Caribe, España y Portugal/Dirección Nacional de Derecho de Autor.

26. Frankenberg, G. (2011). Teoría crítica. Academia, (17), 67-84.

27. Garcés Medrano, A. (2013). Aproximaciones teóricas contemporanéas a la función social de la propiedad. En D. Bonilla, La función social de la propiedad (págs. 29-70). Buenos Aires: Eudeba.

28. García, M. y Rodríguez, C. (2003). Derecho y sociedad en América Latina: propuesta para la consolidación de los estudios jurídicos críticos. En M. García y C. Rodríguez (Edits.), Derecho y sociedad en América Latina: un debate sobre los estudios jurídicos críticos (págs. 15-67). Bogotá: Instituto Latinoamericano de Servicios Legales Alternativos/Universidad Nacional de Colombia.

29. Gargarella, R. (Junio de 2011). El derecho y el castigo: de la injusticia penal a la justicia social. Derechos y libertades (25), 37-57.

30. Geiger, C. (March 4, 2013). The Social Function of Intellectual Property Rights, or How Ethics can Influence the Shape and Use of IP Law. En G. Dinwoodie, Methods and 
Perspectives in Intellectual Property (págs. 153-176). Cheltenham, UK; Northampton, MA: Edward Elgar.

31. Guío Camargo, R. E. (Junio de 2009). Función social y ecológica de la propiedad. Características y alcances. Estudios en derecho y gobierno, 2(1), 51-62.

32. Heath, J. y Potter, A. (2004). Rebelarse vende: el negocio de la contracultura (G. Bustelo, Trad.). Madrid: Taurus.

33. Lamprea, E. (2008). El ingreso ciudadano en el sur global. Hacia la realización de la utopía. En E. Wright, Repensando la distribución: el ingreso básico ciudadano como alternativa para un capitalismo más igualitario (págs 307-358). Bogotá: Siglo del Hombre.

34. Lessig, L. (2001). The future of ideas: The fate of the commons in a connected world. New York: Random House.

35. Lessig, L. (2004). Free culture: How big media uses technology and the law to lock down culture and control creativity. New York: Penguin Press.

36. Lipszyc, D. (2003). Derecho de autor y derechos conexos. Buenos Aires: Unesco/Zavalia/Cerlalc.

37. Lipszyc, D., Villalba, C. y Uchtenhagen, U. (1998). La protección del derecho de autor en el sistema interamericano. Bogotá: Universidad Externado de Colombia
38. López Medina, D. (2014). La “cultura de la legalidad" como discurso académico y como práctica política. Un reporte desde América Latina. En I. Wences, R. Conde y A. Bonilla (Eds.), Cultura de la legalidad en Iberoamérica: desafíos y experiencias. San José, C. R.: Flacso. Obtenido de flacso.org: http://www. flacso.org/sites/default/files/Documentos/libros/secretaria-general/Cultura\%20 de\%20la\%20Legalidad.pdf

39. López, H., Ángel, N., Posada, R. y Moncada, P. (2013). Transformaciones en el espacio de la soberanía. Bogotá, D. C., Colombia: Universidad de los Andes, Facultad de Derecho/Deutsche Gesellschaft für Internationale Zusammenarbeit.

40. Netanel, N. (1998). Asserting copyright's democratic principles in the global arena. Vanderbilt Law Review, 51(2), 231-279.

41. Macías, S. M. R. (2006). El derecho de autor y la reprografía a través del fotocopiado de obras impresas. Mejicali, Baja California: Universidad Autónoma de Baja California, Departamento de Editorial Universitaria.

42. Merges, R. P. y Ginsburg, J. C. (2004). Foundations of intellectual property. New York: Foundation Press.

43. Ministerio de Tecnologías de la Información y las Comunicaciones. (2011). Informe de gestión al Congreso. Obtenido de www. mintic.gov.co: http://www.mintic.gov.co/ portal/604/articles-5258_doc_pdf.pdf 
44. Monroy Rodríguez, J. C. (2009). Estudio sobre las limitaciones o excepciones al derecho de autor y los derechos conexos en beneficio de las actividades educativas $y$ de investigación en América Latina y el Caribe. Ginebra, Suiza: Comité Permanente de Derecho de Autor y Derechos Conexos, ompl. Obtenido de www.wipo.int: http://www. wipo.int/meetings/en/doc_details.jsp?doc_ id=130303.

45. Ortega Díaz, J. F. (2011) La lucha entre el derecho y las posiciones ciberlibertarias: el intercambio de archivos digitales en redes P2P. En Derecho \& TIC 10.0 (págs. 131188). Bogotá: Universidad de los Andes/Editorial Temis, S. A.

46. Organización Mundial de la Propiedad Intelectual. (s. f.). La protección internacional del derecho de autor y de los derechos conexos. Obtenido de wipo.int: http://www.wipo.int/ export/sites/www/copyright/es/activities/ pdf/international_protection.pdf

47. Padilla, J. C. (2013). Definir al autor desde la propiedad intelectual hasta el movimiento derecho y literatura. Estudios Socio-Jurídicos, 15(2), 159-180.

48. Pabón, J. A. (2010). De los privilegios a la propiedad intelectual. Bogotá: Universidad Externado de Colombia.

49. Perilla Granados, J. S. (Diciembre, 2013). Alineación iusteórica desde las licencias Creative Commons. Revista de Derecho privado, 50.
50. Paul, J. R. (2006). ¿Contribuyen las instituciones de comercio internacional al crecimiento y desarrollo económico? En H. Alviar, ¿Es realmente libre el libre comercio? (págs. 49 -151). Bogotá: Siglo del Hombre, Universidad de los Andes.

51. Rodríguez Moreno, S. (2004). La era digital y las excepciones y limitaciones al derecho de autor. Bogotá, Col.: Universidad Externado de Colombia.

52. Sádaba, I. (2007). Sociología de la propiedad intelectual en la era global. [Memoria para optar al grado de doctor]. Universidad Complutense de Madrid. Obtenido de eprints. ucm.es: http://eprints.ucm.es/7707/1/ T30002.pdf

53.Spector, H. (1988). Lineamientos de una teoría justificatoria de los derechos de propiedad intelectual. Derechos Intelectuales, (3), 23-29.

54. Spink, A., Patridge, H. y Jansen, B. (September 4, 2006). Sexual and pornographic Web searching: trends analysis. First Monday. Peer-reviewed journal on the internet, 11(9).

55. Torremans, P. (2004). Copyright and human rights: Freedom of expression, intellectual property, privacy. La Haya/New York: Kluwer Law International.

56. Torres, M. (2001). La copia para uso personal en el entorno digital. (Panorama de la situación actual en las legislaciones de Améri- 
ca Latina). Revista de derecho privado, (26), 127-142.

57. Waisman, A. (2012). Límites al derecho de autor: el interes público en las teorías que justifican la protección. En M. Hevia (Coord.), Teoría y crítica del derecho civil y comercial (págs. 237-257). México: Editorial Fontarama.

58. Waldron, J. (1992). From Authors to Copiers: Individual Rights and Social Values in InteIlectual Property. Chicago-Kent Law Review, 68, 841-887. Obtenido de: http://scholarship.kentlaw.iit.edu/cgi/viewcontent.cgi?article $=2894 \&$ context $=$ cklawreview

59. Waldron, J. (2012). Property and Ownership. Obtenido de Stanford Encyclopedia of Phylosophy: http://plato.stanford.edu/archives/spr2012/entries/property/

60. Weber, M. (1973). Ensayos sobre metodología sociológica. Buenos Aires: Amorrortu.

61. Xalabarder Plantada, R. (2006). Las licencias Creative Commons: ¿una alternativa al copyright? uocpapers, (2).
62.Zapata, F. (2008). Prefacio. En M. Ficsor, Limitaciones y excepciones al derecho de autor en el entorno digital (págs. 15-20). Bogotá: Centro Regional para el Fomento del Libro en América Latina, el Caribe, España y Portugal/ Dirección Nacional de Derecho de Autor.

63. Zapata, F., Schuster, S., Piedras, E., Antequera Parilli, R. y Lipszyc, D. (2007). Diagnóstico del derecho de autor en América Latina. Bogotá: Centro Regional para el Fomento del Libro en América Latina y el Caribe.

64.Zukerfeld, M. (2010). Acceso, conocimiento y estratificación en el capitalismo cognitivo. Obtenido de capitalismoyconocimiento: http://capitalismoyconocimiento.files.wordpress.com/2010/12/hacia-una-teorc3adade-las-clases-para-el-capitalismo-cognitivo. pdf

65.Zukerfeld, M. y Perrone, I. (2007). Disonancias del capital. Buenos Aires: Ediciones Cooperativas. Disponible en: http:// www.ciencia-sociedad.org/wp-content/ uploads/2012/05/Perrone-y-Zukerfeld2007-Disonancias-del-Capital.pdf 